Louisiana State University

LSU Digital Commons

Faculty Publications

Department of Geology and Geophysics

$1-1-2014$

\title{
Triggering and modulation of geyser eruptions in Yellowstone National Park by earthquakes, earth tides, and weather
}

\author{
Shaul Hurwitz \\ United States Geological Survey Western Region \\ Robert A. Sohn \\ Woods Hole Oceanographic Institution \\ Karen Luttrell \\ United States Geological Survey Western Region \\ Michael Manga \\ University of California, Berkeley
}

Follow this and additional works at: https://digitalcommons.Isu.edu/geo_pubs

\section{Recommended Citation}

Hurwitz, S., Sohn, R., Luttrell, K., \& Manga, M. (2014). Triggering and modulation of geyser eruptions in Yellowstone National Park by earthquakes, earth tides, and weather. Journal of Geophysical Research: Solid Earth, 119 (3), 1718-1737. https://doi.org/10.1002/2013JB010803

This Article is brought to you for free and open access by the Department of Geology and Geophysics at LSU Digital Commons. It has been accepted for inclusion in Faculty Publications by an authorized administrator of LSU Digital Commons. For more information, please contact ir@lsu.edu. 


\section{Journal of Geophysical Research: Solid Earth}

\section{RESEARCH ARTICLE \\ 10.1002/2013JB010803 \\ Key Points: \\ - Geysers are insensitive to stresses from \\ Triggering and modulation of geyser eruptions in Yellowstone National Park by earthquakes, earth tides, and weather} earth tides and barometric pressure

- Pool geyser eruption intervals lengthen in response to evaporation and heat loss

- Dynamic stresses >0.1 MPa are required to modulate eruption intervals

Supporting Information:

- Readme

- Table S1 and Figures S1 and S2

Correspondence to:

S. Hurwitz,

shaulh@usgs.gov

\section{Citation:}

Hurwitz, S., R. A. Sohn, K. Luttrell, and M. Manga (2014), Triggering and modulation of geyser eruptions in Yellowstone National Park by earthquakes, earth tides, and weather, J. Geophys. Res. Solid Earth, 119, 1718-1737, doi:10.1002/ $2013 \mathrm{JB} 010803$.

Received 30 OCT 2013 Accepted 31 JAN 2014 Accepted article online 12 FEB 2014 Published online 5 MAR 2014 modulation of volcanic eruptions by external forces.

\author{
Shaul Hurwitz ${ }^{1}$, Robert A. Sohn ${ }^{2}$, Karen Luttrell ${ }^{1,3}$, and Michael Manga ${ }^{4}$ \\ ${ }^{1}$ U.S. Geological Survey, Menlo Park, California, USA, ${ }^{2}$ Woods Hole Oceanographic Institute, Woods Hole, Massachusetts, \\ USA, ${ }^{3}$ Department of Geology and Geophysics, Louisiana State University, Baton Rouge, Louisiana, USA, ${ }^{4}$ Department of \\ Earth and Planetary Science, University of California, Berkeley, California, USA
}

Abstract We analyze intervals between eruptions (IBEs) data acquired between 2001 and 2011 at Daisy and Old Faithful geysers in Yellowstone National Park. We focus our statistical analysis on the response of these geysers to stress perturbations from within the solid earth (earthquakes and earth tides) and from weather (air pressure and temperature, precipitation, and wind). We conclude that (1) the IBEs of these geysers are insensitive to periodic stresses induced by solid earth tides and barometric pressure variations; (2) Daisy (pool geyser) IBEs lengthen by evaporation and heat loss in response to large wind storms and cold air; and (3) Old Faithful (cone geyser) IBEs are not modulated by air temperature and pressure variations, wind, and precipitation, suggesting that the subsurface water column is decoupled from the atmosphere. Dynamic stress changes of 0.1-0.2 MPa resulting from the 2002 M-7.9 Denali, Alaska, earthquake surface waves caused a statistically significant shortening of Daisy geyser's IBEs. Stresses induced by other large global earthquakes during the study period were at least an order of magnitude smaller. In contrast, dynamic stresses of $>0.5 \mathrm{MPa}$ from three large regional earthquakes in 1959, 1975, and 1983 caused lengthening of Old Faithful's IBEs. We infer that most subannual geyser IBE variability is dominated by internal processes and interaction with other geysers. The results of this study provide quantitative bounds on the sensitivity of hydrothermal systems to external stress perturbations and have implications for studying the triggering and

\section{Introduction}

Geysers are rare, with less than 1000 worldwide, of which nearly half occur in the geyser basins of Yellowstone National Park [Rinehart, 1980; Bryan, 1995]. Their rarity results from the delicate balance between water and heat supply required to generate episodic boiling events and the unique geometry of fractures and porous rocks required to focus liquid and steam into an eruptive fountain [e.g., White, 1967; Fournier, 1969; Kieffer, 1989; Ingebritsen and Rojstaczer, 1993, 1996; Kedar et al., 1998; Kiryukhin et al., 2012; Belousov et al., 2013; Vandemeulebrouck et al., 2013; Karlstrom et al., 2013; Shteinberg et al., 2013]. Because of the uncommon balance between these controlling parameters, only a few geysers display relatively constant intervals between eruptions, hereafter IBEs. These geysers are of special interest because they provide an opportunity to examine the responses to transient (e.g., earthquakes and storms) and periodic (e.g., earth tides and barometric pressure) stresses.

Geysers also provide a unique natural laboratory to test hypotheses related to the triggering of volcanic activity because they have many similarities to volcanoes, especially with regard to heat/mass flux, eruption dynamics, and seismicity [Kieffer, 1984]. Many studies have proposed a correlation between volcanic eruptions and environmental factors, such as solid earth tides [e.g., Johnston and Mauk, 1972; Mauk and Johnston, 1973; Hamilton, 1973; Golombek and Carr, 1978; Dzurisin, 1980; Martin and Rose, 1981; Sparks, 1981; Patanè et al., 1994], earthquakes [e.g., Linde and Sacks, 1998; Alam and Kimura, 2004; Selva et al., 2004; Manga and Brodsky, 2006; Walter, 2007; Walter and Amelung, 2007; Eggert and Walter, 2009; Chesley et al., 2012], and precipitation [Mastin, 1994; Matthews et al., 2002], but these analyses are often based on small data sets and/ or limited statistical analysis [Emter, 1997; Neuberg, 2000; Mason et al., 2004]. Geysers have the potential to improve understanding of the processes involved because their eruptions are typically much more frequent than volcanic eruptions, which allows for more robust statistical analyses if the eruption times are carefully documented over long periods of time. 


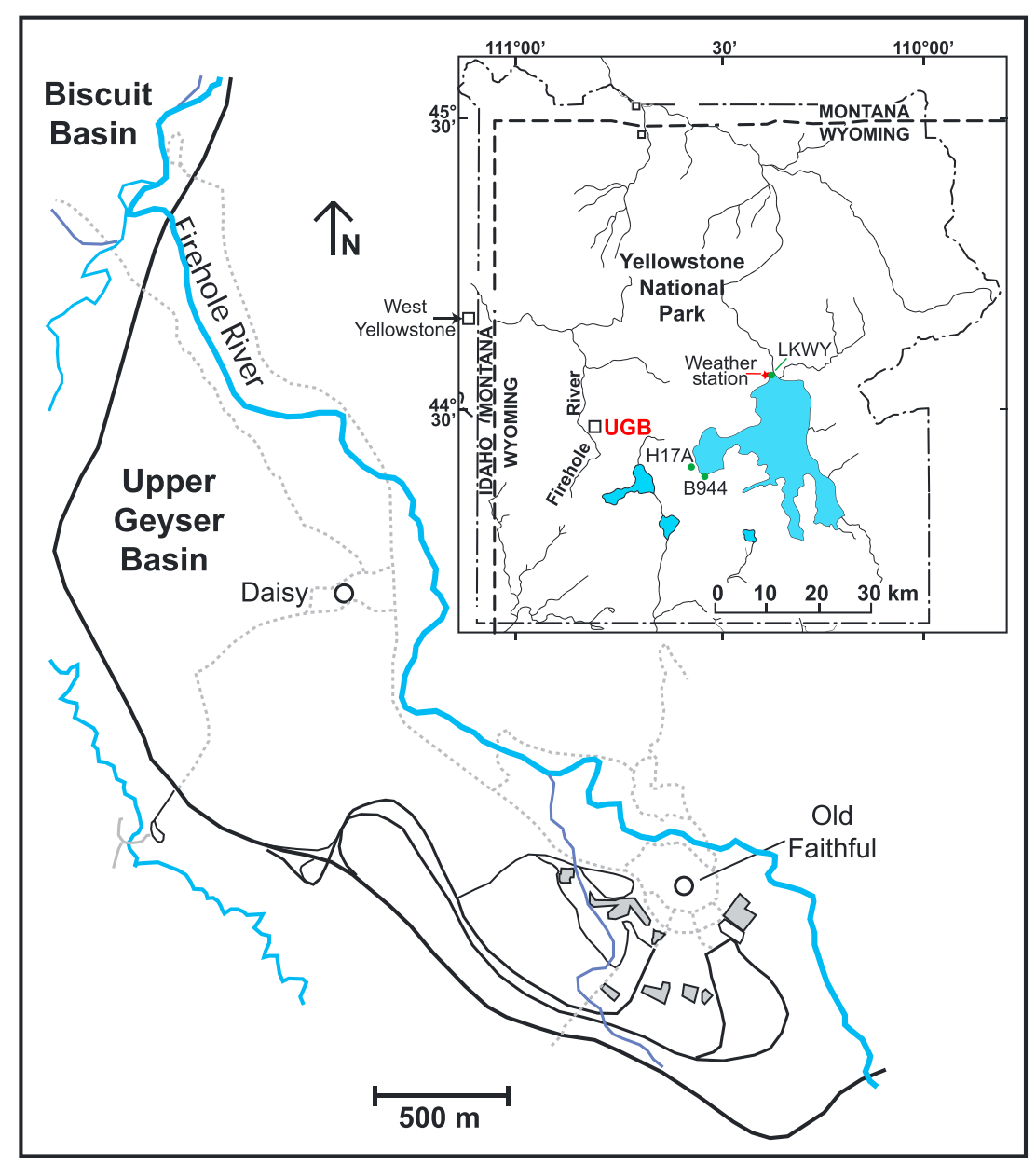

Figure 1. Map showing the location of Daisy and Old Faithful geysers in Yellowstone's Upper Geyser Basin. Inset map of Yellowstone National Park showing the weather station at Yellowstone Lake, seismic stations LKWY and H17A, and strainmeter B944.

The Geyser Observation Society of America monitored eruption times at the Daisy and Old Faithful geysers in Yellowstone's Upper Geyser Basin (Figure 1) between 2001 and 2011, providing a nearly continuous decadal record of IBEs for these two systems. Both of these geysers exhibit relatively uniform subannual eruption intervals, but they have different seasonal patterns [Hurwitz et al., 2008, 2012a], and one (Old Faithful) is a cone geyser, whereas the other (Daisy) is a pool geyser. The decadal records contain $~ 37,000$ and $\sim 58,000$ eruption times for the Daisy and Old Faithful geysers, respectively, which provide an excellent opportunity to conduct rigorous statistical analyses of the cause and effect relationships between eruption intervals and periodic and episodic stresses. The contrasting system types (cone versus pool geyser) allow us to interpret the correlations (or lack thereof) in the context of the fluid dynamic and thermodynamic characteristics of each geyser. Our results place quantitative bounds on the sensitivity of hydrothermal systems to extrinsic perturbations and have implications for the triggering and modulation of volcanic eruptions by environmental forcing.

\section{Previous Studies}

Eruption intervals have been sporadically recorded for the Old Faithful geyser since it was named by the Washburn expedition in 1870 based on the regularity of its eruptions, which occurred every $\sim 74$ min at that time [Langford, 1905]. Since then, eruption intervals were mainly logged by park rangers during the daytime in the summer months [Rinehart, 1969; Stephens, 2002]. These data have shown Old Faithful's IBE distribution to be bimodal, with a small population of short intervals that systematically follow short eruptions [Kieffer, 1984; O'Hara and Esawi, 2013], which has been attributed to internal dynamics within the geyser reservoir 

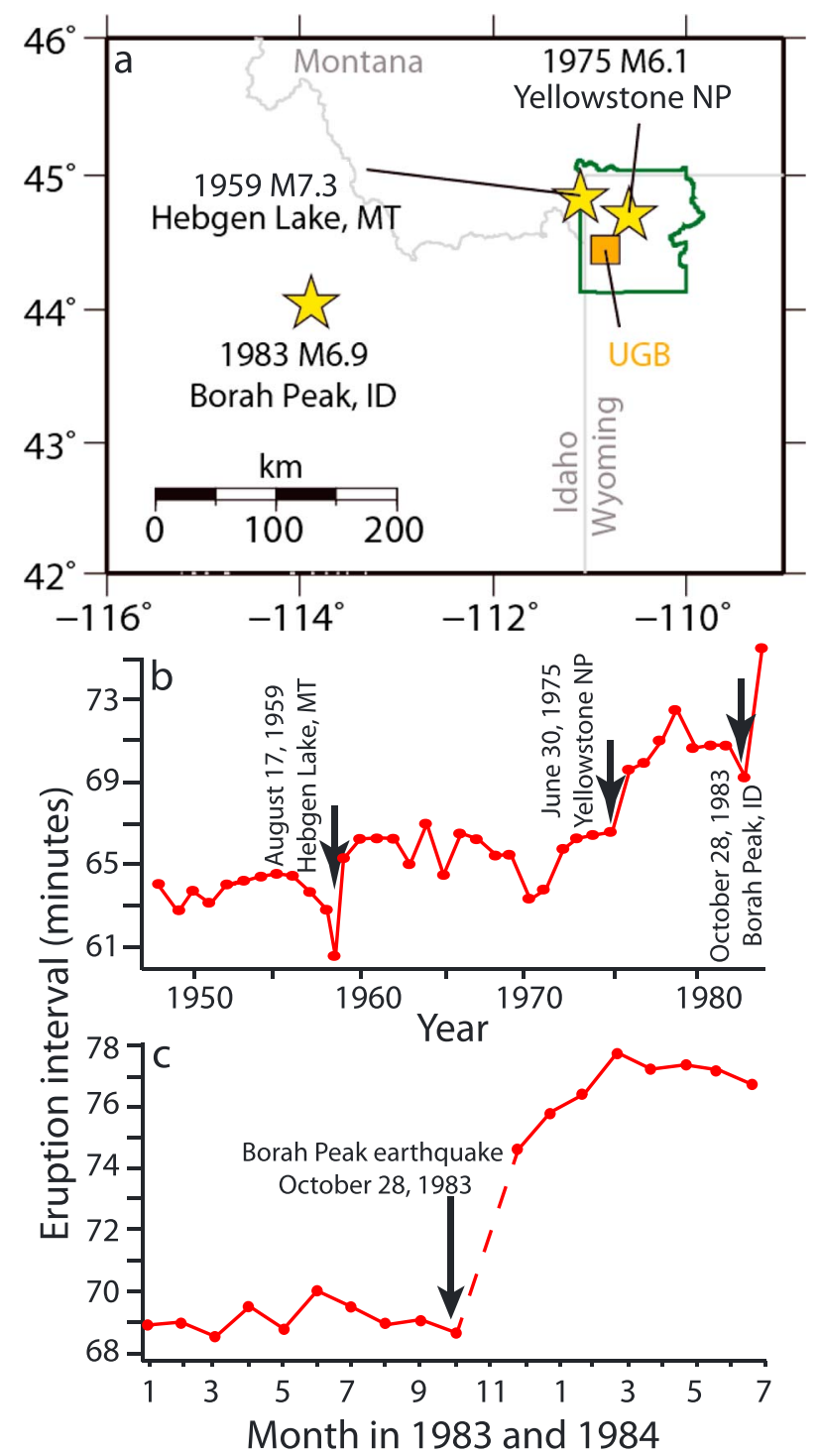

Figure 2. (a) Map showing the location of three large earthquakes in the Yellowstone region. (b) The variation of Old Faithful geyser average annual eruption intervals in response to the three large earthquakes [from Hutchinson, 1985]. (c) The variation of Old Faithful geyser average monthly eruption intervals in response to the 28 October 1983 Borah Peak, Idaho, earthquake. The dashed segment of the curve indicates lack of data.
[O'Hara and Esawi, 2013]. This relationship between eruption duration and IBE is presently used by Yellowstone Park rangers to predict eruption times, and the unique character of the IBE distribution has been modeled by statisticians [Azzalini and Bowman, 1990; Hyndman, 1996; Langrock, 2012; Kottas and Fellingham, 2012] and geoscientists proposing physical models of multiphase eruptions [Nicholl et al., 1994; O'Hara and Esawi, 2013]. There are no equivalent long-term records for Daisy geyser.

Eruption intervals for Yellowstone's geysers are perturbed by both regional and teleseismic earthquakes [Marler, 1964; Rinehart and Murphy, 1969; Marler and White, 1975; Hutchinson, 1985]. This work shows that Old Faithful's IBEs increased significantly (Figure 2) following large regional earthquakes in $1959(M-7.3$ Hebgen Lake [Doser, 1985]), 1975 (M-6.1 Yellowstone National Park [Pitt et al., 1979]), and 1983 (M 6.9 Borah Peak [Payne et al., 2004]). By contrast, the eruption intervals of Daisy geyser decreased from an average of $128 \mathrm{~min}$ to $58 \mathrm{~min}$ following the 1959 Hebgen Lake earthquake [Marler, 1964], which had a dramatic impact on the thermal features within the park. Regarding the response of Yellowstone's geysers to the Hebgen Lake earthquake, Marler and White [1975] wrote, "By the day after the earthquake, at least 289 springs in the geyser basins of the Firehole River had erupted as geysers; of these, 160 were springs with no previous record of eruptions". Dynamic stress perturbations generated by surface waves from distant, teleseismic earthquakes may also perturb IBEs for Yellowstone's geysers, as demonstrated by changes observed following the 2002 M 7.9 Denali earthquake, more than $3000 \mathrm{~km}$ from Yellowstone [Husen et al., 2004a].

Geyser response to earth tides and weather is controversial and was first discussed by Allen and Day [1935]. Later studies [Rinehart, 1972a, 1972b; White and Marler, 1972; Rojstaczer et al., 2003] were limited by either short (weeks) or discontinuous (excluding nights and winters) data sets and have resulted in conflicting interpretations. Rinehart [1972a] concluded that "Both Old Faithful (Yellowstone) and Riverside geysers respond to barometric pressure, but the response is more erratic. At times there is a prominent 30-day phase lag, whereas at others it is impossible to establish any correlations that are convincing" and "Old Faithful (Yellowstone) also responds to tidal forces, similarly exhibiting a 2- to 3-day time delay and being perturbed by the buildup and release of tectonic stresses". These findings were disputed in a comment by White and Marler [1972]. Analysis of continuous eruption interval data for a period of 14 to 101 days from six Yellowstone geysers, including Old Faithful, did not identify earth tide influences in any of the studied 


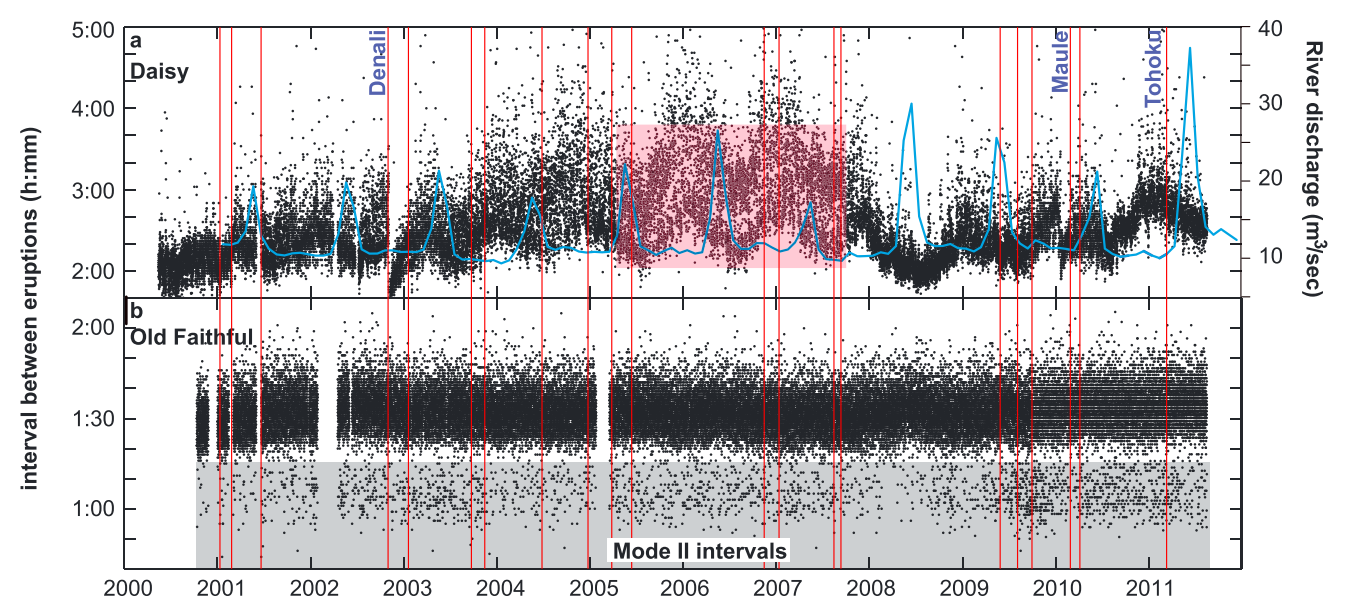

Figure 3. Plot showing the available electronic data of (a) Daisy and (b) Old Faithful geysers intervals between eruptions (IBEs), the major data gaps, and the earthquakes most likely to induce large teleseismic strains in Yellowstone (vertical red lines; Table S1). The shaded red rectangle in Figure 3a marks the period when Daisy's eruption intervals had a bimodal distribution and the grey rectangle in Figure $3 \mathrm{~b}$ represents mode II IBEs that are shorter than $75 \mathrm{~min}$. The blue curve in Figure 3a represents the monthly average discharge of the Madison River measured at U.S. Geological Survey gauge near West Yellowstone, MT (station ID 06037500). River discharge mimics snow melt and water recharge into the subsurface.

geysers, but the study found that long-period atmospheric-pressure variations greater than 5 mbars $(0.5 \mathrm{kPa})$ may influence eruption intervals [Rojstaczer et al., 2003]. Systematic examination of Yellowstone geysers' response to wind storms has not been carried out, but anecdotal evidence suggests that "the intervals of Daisy were measurably lengthened whenever a stiff breeze blew across the Daisy and the large, shallow basin that is filled during the basin of overflow" [Marler, 1951]. Similar observations of Daisy's response to wind storms were also reported by Bower [1994]. A more quantitative correlation between wind strength and direction and geyser activity was demonstrated for geysers in Geyser Flat, Whakarewarewa, New Zealand [Weir et al., 1992].

In summary, previous investigations of geyser response to earthquakes and environmental stresses have raised many interesting issues, but key questions remain unanswered. It is clear that geysers can respond to large regional earthquakes, but whether the IBE should increase or decrease and what are the thresholds for these perturbations have not been determined. Similarly, it appears as though some geysers can respond to dynamic stress perturbations from surface waves generated by distant, teleseismic earthquakes, but here, again, no criteria have been established to predict what stress type (dilation, shear, etc.) controls the process and how large these perturbations must be. Geyser response to environmental stresses remains controversial, primarily because essentially all of the results to date have been based on limited data with questionable statistical significance. Rigorous analyses based on statistically significant sample sizes are required to address all of these issues.

\section{Data Sets and Methods}

Eruption times and intervals for the Old Faithful and Daisy geysers were obtained from data collected by the Geyser Observation Society of America (http://www.geyserstudy.org/) using temperature sensors located in the geysers' outflow channels. The Old Faithful data span the interval from 2001 to 2011 with a sample interval of $1 \mathrm{~min}$ from 2001 and 2009, and $1 \mathrm{~min}$ and $6 \mathrm{~s}$ from 2009 to 2011. Daisy's sampling interval was more varied. (e.g., longer in the winters to preserve memory); however, it is always $\leq 2 \mathrm{~min}$ (R. Taylor, Geyser Observation Society of America, written communication, 2012). Eruption times were extracted from the temperature records by determining when water temperature increased sharply, resulting in a pointprocess eruption catalog for the two geysers. The 2001-2011 Daisy catalog contains 37,467 intervals, and the 2001-2011 Old Faithful catalog contains 58,497 intervals, of which 2323 intervals (4\%) are shorter than $75 \mathrm{~min}$ and defined as mode II intervals (Figure 3). Instrumentation problems resulted in occasional data gaps throughout the $\sim 11$ years of monitoring, which we define as intervals where the eruption interval for each geyser is greater than twice the average value. There were 315 data gaps in the Daisy records and 21 data 
gaps in the Old Faithful records. The average annual IBE for Old Faithful geyser varied between 91 and 93 min, and the distribution between the long and short eruptions varied slightly. The average and standard deviation of Daisy geyser IBE ranged between $133 \pm 16$ min in 2008 and $180 \pm 32$ min in 2006 (supporting information Figure S1). Between mid-2005 and mid-2007, Daisy geyser's IBE also had a bimodal distribution (Figure 3a). This bimodal distribution was superimposed on large seasonal variations, and it occurred in both the summer and winter and during periods of snowmelt and high water recharge and during periods with little precipitation.

Weather data (air temperature, barometric pressure, wind speed, and precipitation) for the 2001-2011 period were obtained from the National Climatic Center station at Yellowstone Lake, located at an elevation of $2400 \mathrm{~m}, 35 \mathrm{~km}$ from the Upper Geyser Basin (Figure 1). Although there is a weather station near Old Faithful, it does not collect barometric pressure and temperature data and thus is not suitable for our analyses. We compared the climate center data from Yellowstone Lake to noncontinuous barometric pressure data collected at the West Yellowstone, Montana airport (Figure 1), and found that barometric pressure fluctuations are in-phase across this broad region, which justifies the use of the climate data from Yellowstone Lake for our study. Theoretical phase and amplitude of earth tides were calculated using the SPOTL software package [Agnew, 2012].

We use cross-spectral methods to assess correlation between eruption intervals and periodic processes (e.g, earth tides, barometric pressure, and air temperature). For the spectral analysis, we selected the time window from 1 April 2005 to 31 July 2011 (6.3 years of data), which excludes all of the major data gaps for both geysers. Linear interpolation was used to fill in gaps shorter than three average eruption intervals. Overall, the 6.3 year Old Faithful geyser data set contains 36,260 eruptions, and the 6.3 year Daisy geyser data set contains 20,577 eruptions. We estimate spectra for the point-process eruption interval data using the method of Brillinger [1975], wherein we generate 15 min bins for our time series and assign values of 1 to those bins containing eruptions and values of 0 to the others. Smaller bin sizes yielded similar results, but with more background noise. Spectral estimates were obtained using the multitaper method [Thomson, 1982] with adaptive weighting [Percival and Walden, 1993]. Multitaper estimation reduces the bias resulting from spectral leakage while minimizing the information loss inherent in the use of conventional tapers and avoiding the need for prewhitening. Adaptive weighting minimizes the mean square error of the spectral estimates by determining the weights for each taper by an iterative procedure that accounts for the (nonwhite) spectral content of the data. Cross-spectral estimates for the geyser eruption interval data with respect to the environmental parameters (earth tides, barometric pressure, and air temperature) were made in the same fashion (multitaper with adaptive weighting) after interpolating the environmental time series data onto the same 15-min grid as the eruption catalogs.

To provide a quantitative test for the observations suggesting that large wind storms are followed by lengthening of Daisy geyser's IBEs [Marler, 1951; Bower, 1994], we define a wind storm as an event with at least 3-hourly wind speed measurements of $\geq 7 \mathrm{~m} \mathrm{~s}^{-1}$ within a $12 \mathrm{~h}$ period. We define a significant Daisy geyser response to a wind storm when at least one of the IBEs during the storm is more than one standard deviation from the average IBE of the month preceding the storm. We define a significant response of Daisy geyser to precipitation if any of the IBEs in the $3 \mathrm{~h}$ following a recording of $\geq 7 \mathrm{~mm} \mathrm{~h}^{-1}$ is more than one standard deviation from the average IBE of the month preceding the precipitation recording. These wind and precipitation criteria are representative of typical storms observed in the data, and our conclusions are robust to the exact choice of wind speed and precipitation rate thresholds.

To investigate the effect of dynamic stresses from distant earthquakes on geyser eruptions, we first identified a subset of earthquakes that were expected to produce the largest strains in the Yellowstone area based on their estimated seismic energy density, $\varepsilon\left(\mathrm{J} \mathrm{m}^{-3}\right)$, a parameter that is approximately proportional to the square of the peak ground velocity, which in turn is proportional to the dynamic strain. An empirical relation between $\varepsilon$, earthquake magnitude $M$, and the distance $r(\mathrm{~km})$ from the source is given by [Wang and Chia, 2008]:

$$
\log r=0.48 M-0.33 \log \varepsilon-14
$$

We also use data from borehole strainmeter B944 located at Grant Village (Figure 1) that has been operating continuously since 2009 and records the 2-D horizontal strain tensor during that time [Luttrell et al., 2013]. The 


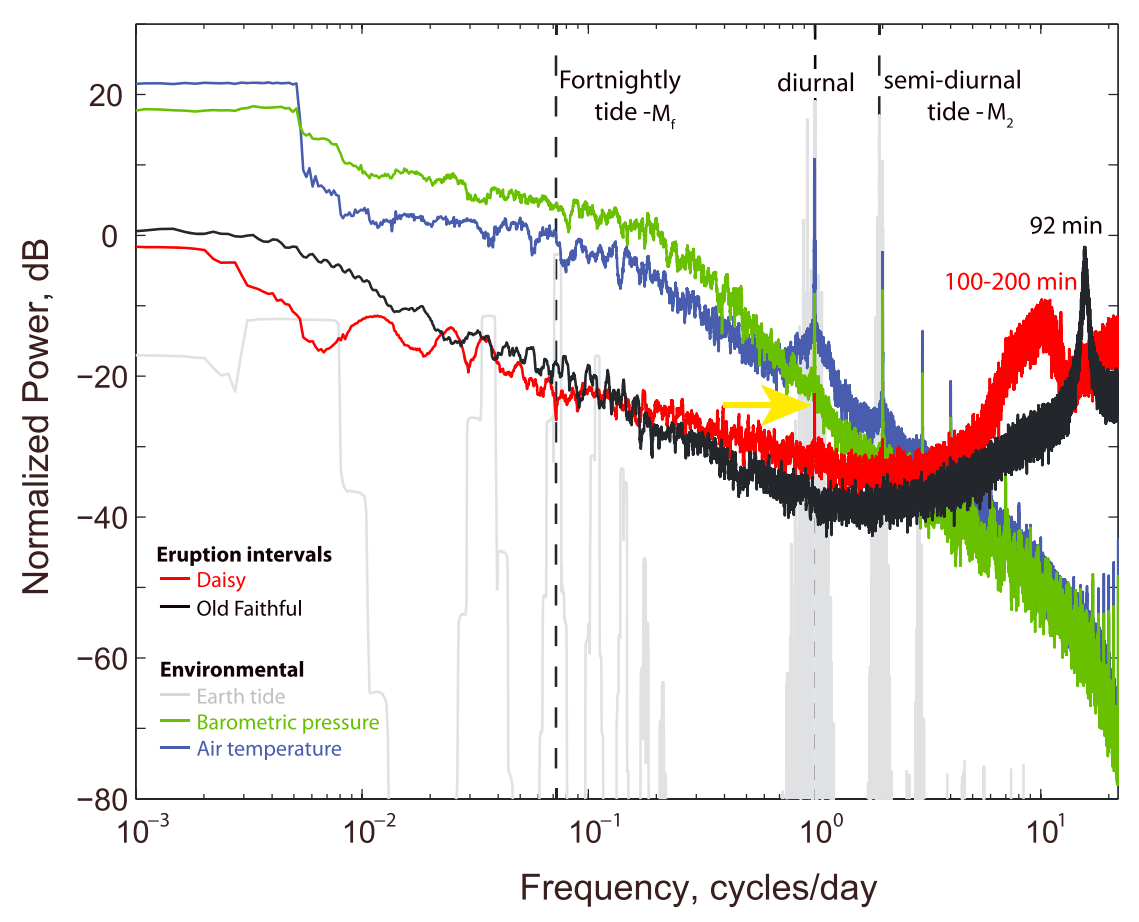

Figure 4. Power spectra of Old Faithful (black) and Daisy (red) geyser eruption intervals (IBEs), earth tides (grey), air pressure (blue), and temperature (green). The vertical dashed lines represent the frequencies of the three major earth tides.

strainmeter is maintained by (UNAVCO) (www.unavco.org/), and data are archived by Incorporated Research Institutions for Seismology (IRIS) (www.iris.edu/). By comparing the observed teleseismic strain to the predicted $\varepsilon$ from an earthquake, we determine that the criteria of $\varepsilon>10^{-4.5} \mathrm{~J} \mathrm{~m}^{-3}$ and $M>6.8$ applied to the full U.S. Geological Survey National Earthquake Information Center (NEIC) catalog best predict which earthquakes produce high dynamic strain in Yellowstone. The resulting catalog (Table S1) includes 21 earthquakes during the period of IBE record. While the above criteria were used to identify the subset of earthquakes most likely to induce high dynamic stress in Upper Geyser Basin, subsequent analysis used observations of peak dynamic stress [Hill et al., 1993] to compare teleseismic events.

We hypothesize that teleseismic stresses could affect geyser IBE via two processes. The first is by altering the permeability structure of the geyser's conduit or reservoir, which could result in either an increase or a decrease of IBE and could be either irreversible (e.g., a new IBE state is attained) or reversible, where after some period with anomalous IBE, the intervals will return to the pre-earthquake values. These scenarios are common hydrologic responses to earthquakes [Manga and Wang, 2007; Manga et al., 2012]. We define a geyser response of this sort as one in which the range of IBEs after an earthquake is nonoverlapping with the range of IBEs before the earthquake. To avoid bias by small numbers of outlier eruptions, we define the range as the time between the 0.05 and 0.95 quantiles of the respective populations. We tested the catalog of earthquakes most likely to produce high dynamic stress (supporting information Table S1) for populations of $10,20,50$, and 100 IBEs after an earthquake ( 1, 2, 5, and 10 days of eruptions), comparing them with the population of 360 IBEs before an earthquake ( 1 month) of eruptions (supporting information Figure S2).

We also consider a second process where bubble nucleation from steam-saturated water can decrease the period required to attain conditions for an eruption [Steinberg et al., 1982]. This process is expected to occur only when the water in the geyser reservoir is at, or near, boiling conditions and when seismic waves are reverberating locally. Such a response should be manifested by one or two short eruption intervals immediately following the earthquake. We expect that if the short IBEs are a response to an earthquake, the relation between eruption duration and the following IBEs [Kieffer, 1984] will not be maintained. We obtained partial information on eruption duration from the Old Faithful visitor center notebook logs that were transcribed by the Geyser Observation Society of America (http://www.geyserstudy.org/ofvclogs.aspx). 


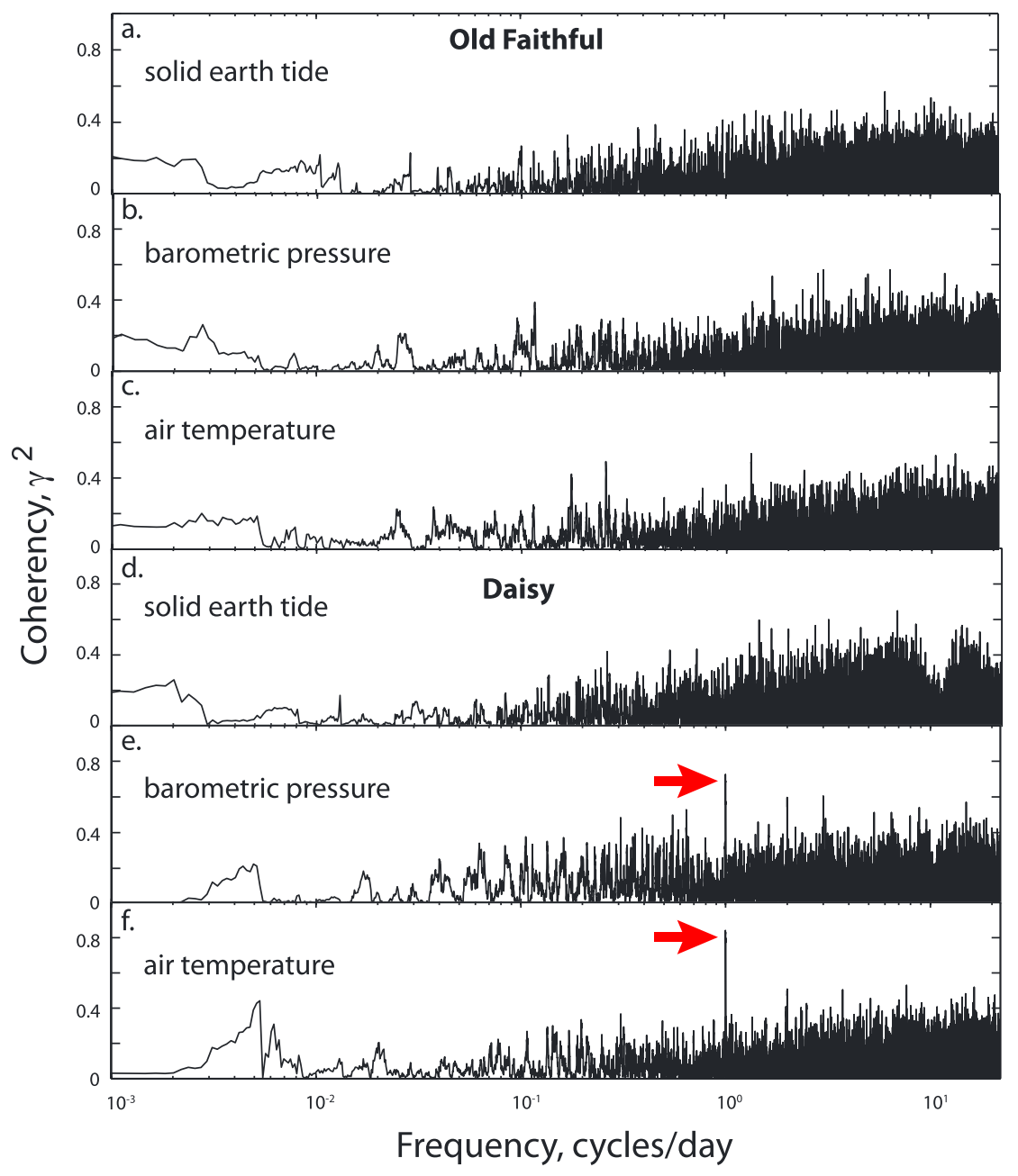

Figure 5. Plot showing the coherency of the spectral cross correlation between interval between eruptions (IBE) of Old Faithful geyser and (a) solid earth tide, (b) barometric pressure, and (c) air temperature, and between interval between eruptions of Daisy geyser and (d) solid earth tide, (e) barometric pressure, and (f) air temperature. The red arrows point to the high-amplitude spectral peaks at a period of 1 day.

\section{Results}

\subsection{Geyser Response to Periodic Processes}

We examined the spectral characteristics of the geyser eruption catalogs and the periodic environmental processes (earth tides, barometric pressure, and air temperature) from 1 April 2005 to 31 July 2011 (6.3 years) (Figure 4). Power spectra for the environmental parameters peak at orbital periods, with the strongest peaks in the diurnal and semidiurnal frequency bands (Figure 4). The geysers have broad spectral peaks covering their respective eruption interval ranges, with Old Faithful exhibiting a narrower peak as a consequence of its smaller degree of deviation (see supporting information for annual eruption interval histograms and statistics). The power spectrum for the Daisy geyser eruption intervals contains a sharp spectral peak at 1 cycle per day, where there are also peaks in the environmental time series data. The Old Faithful eruption interval power spectrum does not have any peaks at the orbital frequencies.

Cross-spectral coherency between the environmental data and the geyser intervals are shown in Figure 5. The Old Faithful eruption intervals are not coherent with the environmental data at any frequency, indicating that they are not influenced by earth tides, barometric pressure, or air temperature. The Daisy eruption intervals are not coherent with earth tide, but they are coherent with both barometric pressure and air temperature at the 1 cycle per day frequency, with the highest levels $(>0.8)$ for air temperature. These results indicate that Daisy's 


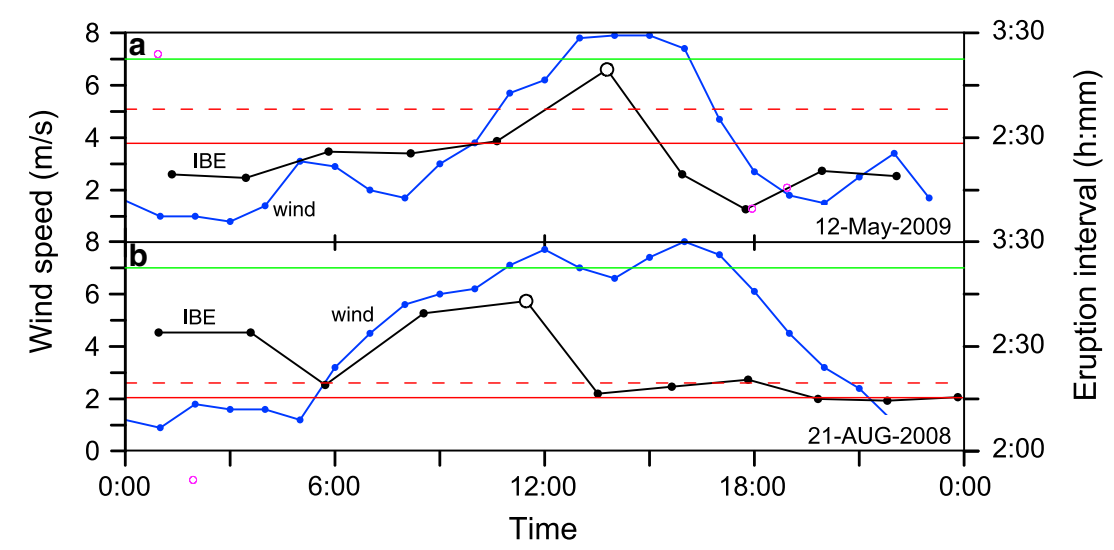

Figure 6. The variation of Daisy geyser to two of the largest wind storms in (a) May 2009 and (b) August 2008. Black curves and symbols represent geyser IBE, blue curves and symbols represent wind speed, horizontal solid green lines represent wind speeds of $7 \mathrm{~m} \mathrm{~s}^{-1}$, horizontal solid red lines represent the average geyser IBE of the 30 days prior to the storm, and the horizontal dashed red lines represent the 30 day average plus one standard deviation. The empty black circles represent the anomalously long IBE associated with the wind storm.

eruption intervals are not influenced by solid earth tides but that they do respond to atmospheric processes, with air temperature being slightly more strongly correlated than barometric pressure.

\subsection{Geyser Response to Wind and Precipitation}

There were 11 events with at least 3-hourly wind speed measurements of $\geq 7 \mathrm{~m} / \mathrm{s}$ within a $12 \mathrm{~h}$ period between 2001 and 2011, although some storms might be missing due to data gaps. A maximum wind speed of $9.3 \mathrm{~m} / \mathrm{s}$ was measured on 29 December 2008, and all large wind storms were associated with a barometric pressure decrease of 3-8 mbar (Figure 6). In 8 of the 11 storms, at least one Daisy IBE during the storm was longer than the monthly average plus one standard deviation. During two of the storms, no anomalous IBE was recorded, and in one of them, there was a single IBE that was shorter than the monthly average minus one standard deviation. During one of the storms (15 December 2006), two of the IBEs were $11 \mathrm{~h}$ and $8 \mathrm{~min}$ and $15 \mathrm{~h}$ and $50 \mathrm{~min}$; however, we suspect that these result from instrument malfunction, because these IBEs are much longer than other responses to wind storms and much longer than other IBEs during that period. None of the 11 wind storm events were associated with anomalous IBEs of Old Faithful geyser. Daisy and Old Faithful geysers' IBEs were not modulated in the 3 hours following any of the seven precipitation events of $\geq 7 \mathrm{~mm} / \mathrm{h}$. We conclude that wind and rain do not affect the timing of Old Faithful's eruptions but that strong wind storms may lengthen the interval between Daisy's eruptions.

\subsection{Geyser Response to Earthquakes}

We calculated the seismic energy density (equation (1)) in Yellowstone for the full NEIC catalog (Figure 7) and identified the 21 earthquakes most likely to produce high dynamic strain (Table S1). Of these, the earthquakes that produced the largest seismic energy density during our study period are the March 2011 M-9.1 Tohoku, Japan, earthquake; the June 2005 M-7.2 Northern California earthquake; the April 2010 M-7.2 Sierra El Mayor, Mexico, earthquake; the February 2001 M-6.8 Nisqually, Washington, earthquake; and the November 2002 M-7.8 Denali, Alaska, earthquake (Figure 7). We tested each earthquake in Table S1 for both a long-term permeability-driven response and a short-term bubble nucleation-driven response, as described in section 3, at both Old Faithful and Daisy geysers.

We first assess the short-term response of both geysers to the 21 earthquakes in Table S1. At Daisy, only two earthquakes were followed immediately by unusual IBEs. A shortened interval occurred following the 2002 Denali earthquake (Figure $8 \mathrm{~b}$ ), but this should be considered the beginning of the longer-term response described below, rather than an immediate response to bubble nucleation. A very long interval ( $517 \mathrm{~min}$ ) occurred following the 2011 Tohoku earthquake. However, this is likely due to a gap in IBE data, particularly because the eruption interval was already anomalously long before the earthquake occurred. As such, we find no indication that Daisy IBEs are affected by earthquakes in this way. 

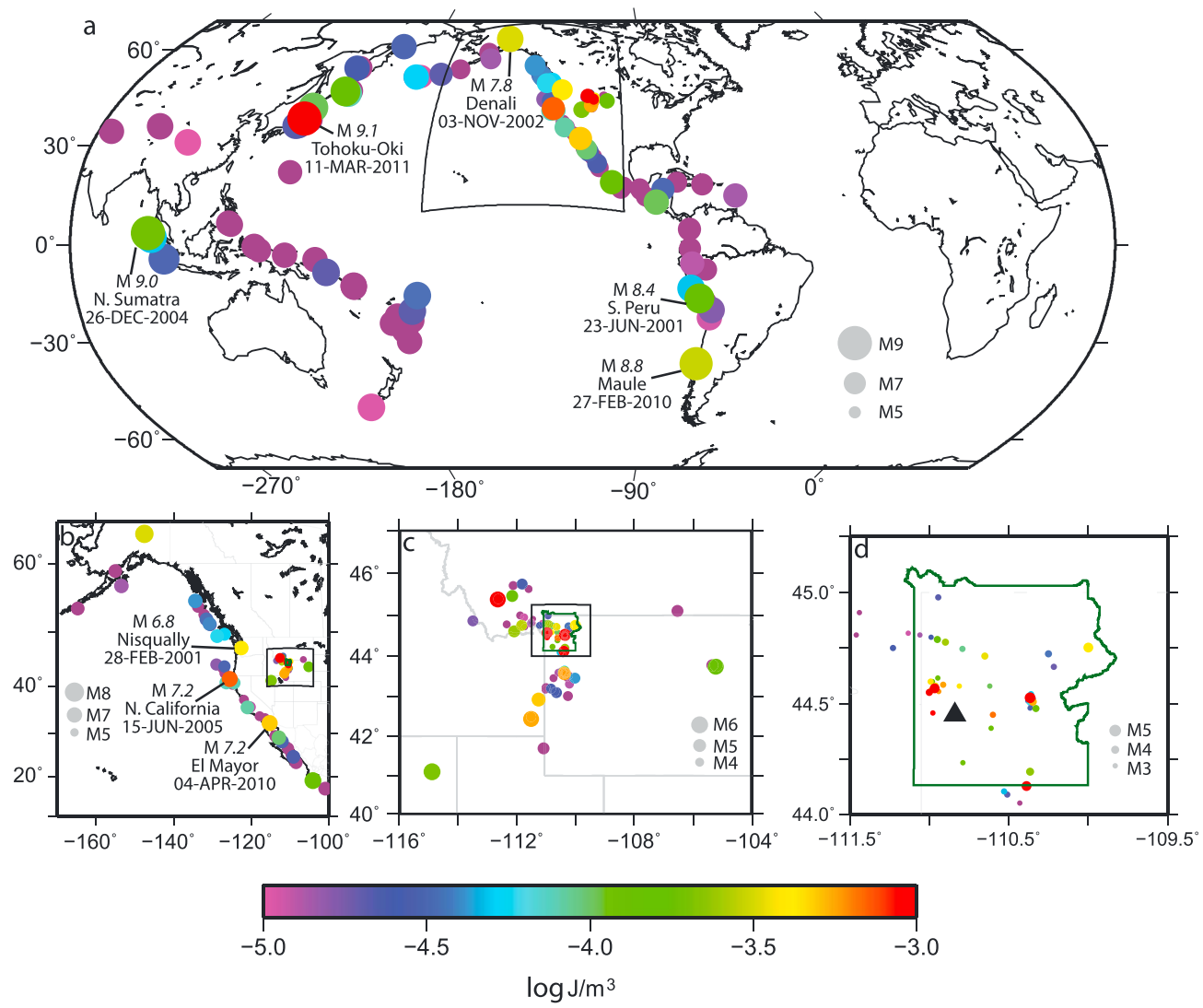

Figure 7. Maps showing location of earthquakes that produced seismic energy density [Wang and Chia, 2008] in Yellowstone of $\varepsilon \geq 10^{-5} \mathrm{Jm}^{-3}$ (a) globally, (b) in the western United States and Alaska, (c) in the region around Yellowstone, and (d) in Yellowstone National Park and vicinity.

Because of Old Faithful's bimodal distribution (4\% of the catalog were mode II intervals), a significant shortterm response to an earthquake would be indicated by (1) extremely short intervals (shorter than other mode II intervals, e.g., <50 min.), (2) if all earthquakes that induced dynamic stress above a certain threshold were followed by a mode II interval, or if the (3) empirical relation between eruption duration and the following IBEs [Kieffer, 1984] was perturbed. None of the 21 earthquakes listed in Table S1 were followed by an IBE that was shorter than $50 \mathrm{~min}$, and none of the earthquakes were followed by two or more consecutive mode II intervals. (Unfortunately, there are no IBE data for Old Faithful geyser during the February 2001 Nisqually earthquake.) However, three of the earthquakes were followed by a mode II interval within the $2 \mathrm{~h}$ following the earthquake. These are the June 2001 M-8.4 Southern Peru earthquake (Figure 8a), the August 2009 M-6.9 Gulf of California earthquake (Figure 8d), and the March 2011 M-9.1 Tohoku, Japan (Figure 8f), earthquakes. Based on the transcribed notebook logs (http://www.geyserstudy.org/ofvclogs.aspx), the short intervals following the Southern Peru and Gulf of California earthquakes were preceded by short-duration eruptions, suggesting that the short IBE was not in response to the earthquake. The Tohoku earthquake occurred during the night in Yellowstone, so that the eruption was not observed.

The only long-term response to an earthquake at either geyser, defined as one in which the range of IBEs for a period after an earthquake is nonoverlapping with the range of IBEs before the earthquake, is Daisy's response to the November 2002 Denali earthquake (Figure 8b). Following the earthquake, the IBE population attained a new state with no overlap with the IBE population before the earthquake. To further assess the uniqueness of the Daisy geyser's IBE change in response to the Denali earthquake, we performed a Monte Carlo simulation of 1000 synthetic earthquake catalogs, each with 21 random times during the Daisy IBE record. We then tested these synthetic catalogs for a long-term IBE change to each synthetic earthquake in the same way. In these tests, only $2 \%$ of synthetic catalogs contained at least one event time with no overlap between the 360 IBEs before the event and 10, 20, 50, or 100 IBEs after that event. These findings confirm that 

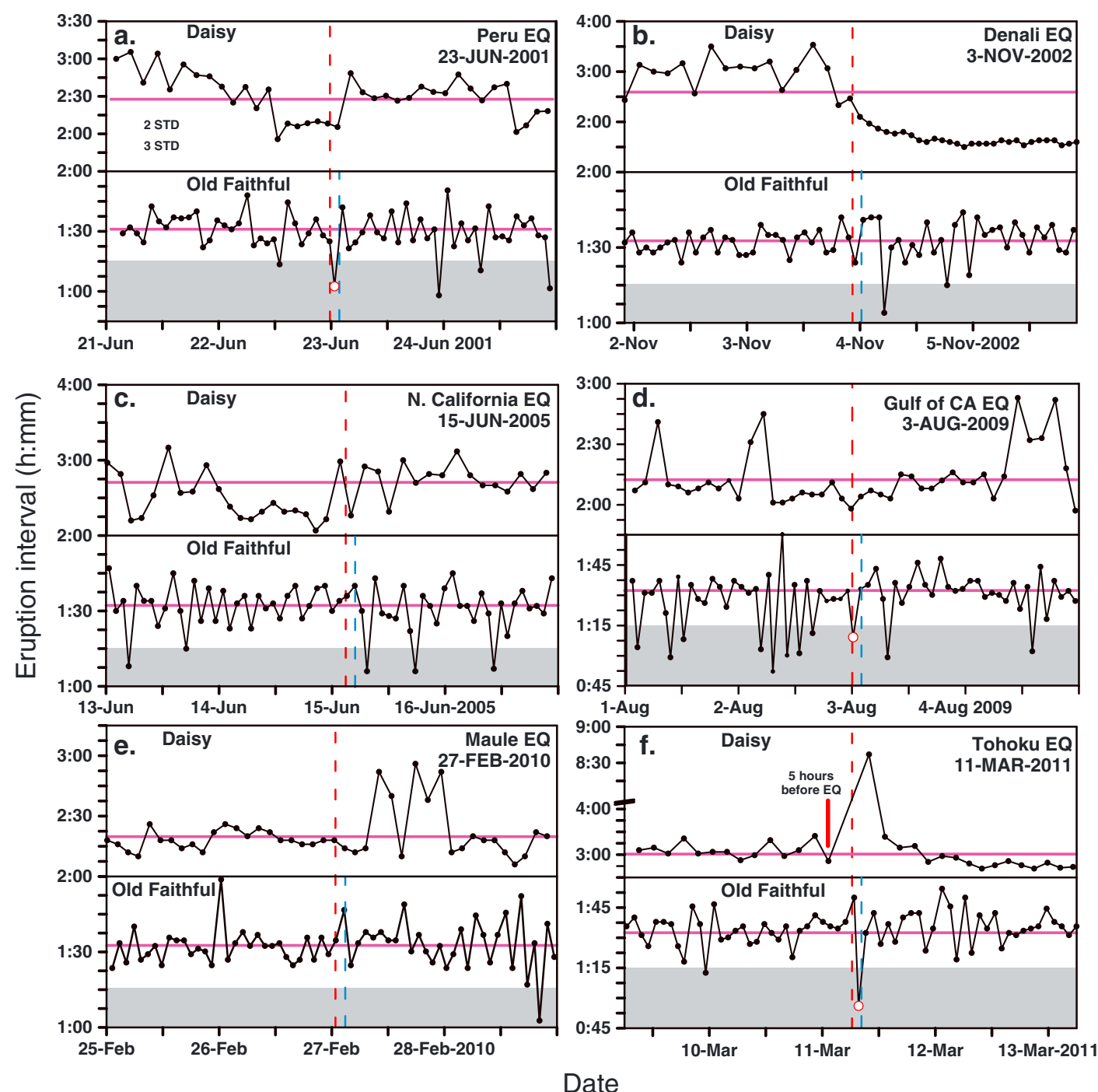

Figure 8. Interval between eruptions (IBE) (black circles) of Daisy and Old Faithful geysers before and after (a) June 2001 Southern Peru earthquake; (b) November 2002 Denali, Alaska, earthquake; (c) June 2005 Northern California earthquake; (d) August 2009 Gulf of California earthquake; (e) February 2010 Maule, Chile, earthquake; and (f) March 2011 Tohoku-Oki earthquake offshore Japan. (The first and very long Daisy geyser IBE following the Tohoku-Oki earthquake is likely due to instrument malfunction.) The vertical dashed red line represents the time of surface wave arrival in Yellowstone, the vertical dashed blue lines represent $2 \mathrm{~h}$ after surface wave arrival in Yellowstone, and the grey rectangles denote Old Faithful geyser mode II ( $<75 \mathrm{~min}$ ) intervals. Red circles with white filling represent mode II intervals within $2 \mathrm{~h}$ of the earthquake.

the only significant response of either Old Faithful or Daisy geysers during the period of recorded IBEs (2000-2011) is Daisy's response to the 2002 Denali earthquake.

It should be noted that during the IBE record, an earthquake swarm occurred beneath the Madison Plateau, near the northwest boundary of the Yellowstone caldera, 16-17 km from Old Faithful. It began on 17 January 2010, continued for 3 weeks, and included 17 earthquakes with magnitudes greater than 3.0 [Shelly et al., 2013]. The largest earthquake in the swarm had a magnitude 4.2 (seismic energy density of $\log \varepsilon=-1.84$; Figure 9). Daisy IBEs are highly variable during this period and generally decrease throughout the swarm (Figure 9a). However, this behavior seems to be part of a longer decrease that began before the swarm, so we cannot conclude that they are related. Two of the largest earthquakes in the swarm occurred within 15 min on 21 January and were between two eruptions whose intervals were longer than either the preceding or following 10 intervals (Figure 9b). Because of the large variability in IBEs before these two earthquakes, we cannot conclusively define the IBE behavior afterward as anomalous. 


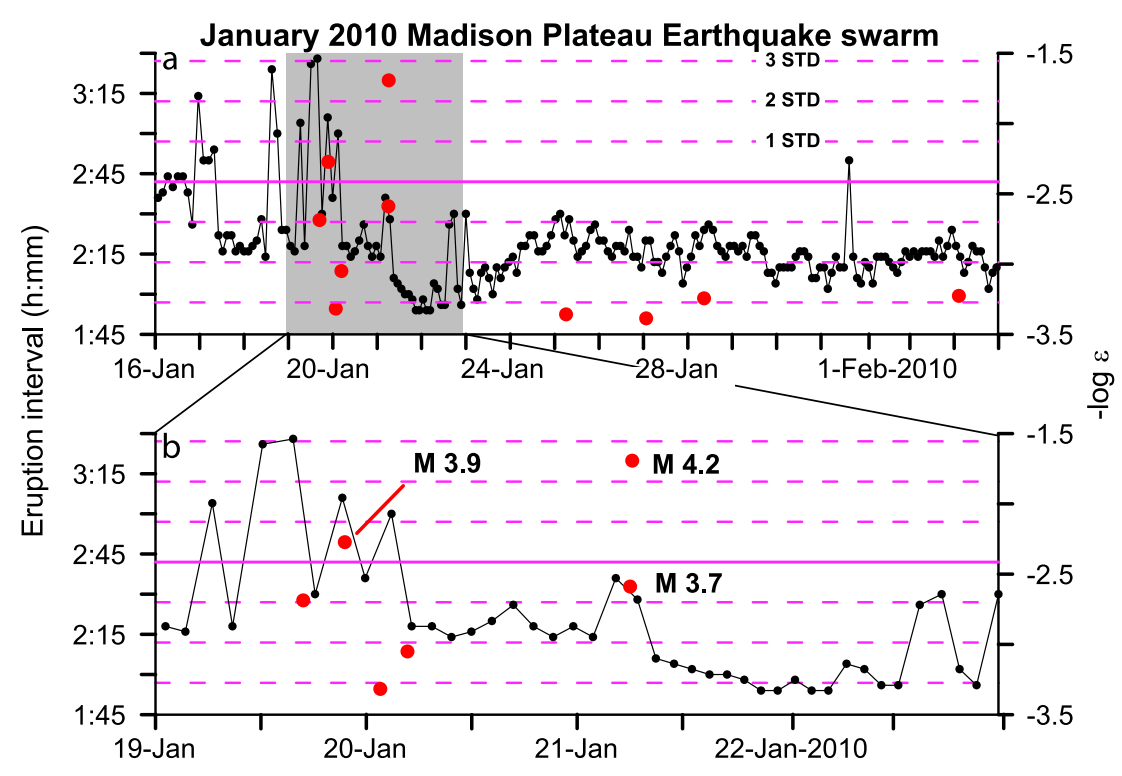

Figure 9. (a) Daisy geyser interval between eruptions (IBE) (black circles) and seismic energy density (red circles) of earthquakes with $M>3.0$ during the January 2010 Madison Plateau earthquake swarm [Shelly et al., 2013]. The solid horizontal magenta line represents the average IBE for the 30 days prior to the onset of the swarm, and the dashed horizontal magenta lines are for 1, 2, and 3 standard deviations. (b) Zoomed view on a section of Figure 9a.

\section{Discussion}

We used a variety of statistical tests to examine and quantify the response of Old Faithful and Daisy geysers to earthquakes, earth tides, and weather for the period between 2001 and 2011. The analysis demonstrates the different responses of the two geysers, allows us to place quantitative bounds on their sensitivity to extrinsic perturbations, and provides the basis for discussing the possible implications for the triggering and modulation of volcanic eruptions by environmental forcing.

\subsection{Geyser and Volcano Response to Earth Tidal Stresses}

Earth tides result in compression of the solid earth at low tide and expansion at high tide [Agnew, 2007] that are commonly manifested by semidiurnal and diurnal water level oscillations in well-aquifer systems [Bredehoeft, 1967; Hsieh et al., 1988; Roeloffs, 1996]. The stress changes induced by the semidiurnal $\left(M_{2}<0.004 \mathrm{MPa}\right)$ and the fortnightly $\left(M_{\mathrm{f}}>0.001 \mathrm{MPa}\right)$ earth tides are much smaller than the strengths of rock in tensile failure, which are in the range of 1-10 MPa [e.g., Lockner and Beeler, 1999; Beeler and Lockner, 2003]. Thus, earth tides are not expected to modulate geyser IBEs by fracturing and subsequent permeability changes but could potentially modulate IBEs by poroelastic contraction or expansion of deep thermal reservoirs, or the shallow geyser reservoir and conduit [Hutchinson et al., 1997; Vandemeulebrouck et al., 2013]. These stresses in turn could advance or delay bubble nucleation and growth and decrease or increase the time required to attain critical conditions for the eruption. Further, a recent study demonstrated that poroelastic stresses were sufficient to cause measurable deformation of Old Faithful geyser in Calistoga, California [Rudolph et al., 2012]. The absence of a statistically significant IBE modulation of Old Faithful and Daisy by earth tides is consistent with previous studies [White and Marler, 1972; Rojstaczer et al., 2003] and suggests that poroelastic pressure perturbations $>0.004 \mathrm{MPa}$ are required to modulate IBEs.

The lack of correlation between solid earth tides and geyser IBE might suggest that a correlation between solid earth tides and volcanic eruptions proposed by many studies should not be expected [Neuberg, 2000; Mason et al., 2004]. First, in contrast to the thousands of geyser IBEs, only a small number of eruptions from a single volcano are typically available for statistical tests, and in most cases the start times of these eruptions are not precise enough to allow for a comparison with the semidiurnal tide [Emter, 1997]. Therefore, most studies invoked correlations between eruptions and lunar fortnightly tides, which are a modulation of the larger amplitude semidiurnal and diurnal tides. Second, pressure decrease and volatile loss in ascending magmas promote crystallization and formation of multiphase suspensions. These suspensions can 
significantly increase magma viscosity and impart a yield strength at a critical threshold, typically in the range of 10-50\%, crystals [Saar et al., 2001; Llewellin and Manga, 2005; Walsh and Saar, 2008]. Even if we assume that subliquidus erupting magmas have no yield strength, the timescale of the response to instantaneous (tidal) perturbations is likely to be delayed because of the magma's high viscosity. This possible lag would mask a statistical correlation in the time domain between tidal phase and eruption.

\subsection{Geyser Response to Weather Variability}

The IBEs of Old Faithful geyser are not modulated by air temperature and pressure variations, wind storms, or precipitation, indicating that in cone geysers, the subsurface water column is thermally decoupled from the atmosphere and that the relatively small volume of water in the conduit that senses the atmosphere does not exert a major control on the initiation of eruptions. In contrast, the IBEs of Daisy (pool geyser) are modulated daily (Figure 6) and seasonally [Hurwitz et al., 2008, 2012a]. The eruptions of Daisy are longer in the winter and at night when air temperature is colder and air pressure is lower. The coincidence of shorter IBEs with high barometric pressure implies that decompression boiling in response to barometric pressure variations does not control the initiation of eruptions. Rather, the coincidence of shorter eruptions with cold air temperature (large water-air temperature difference) and the lengthening of IBEs during large wind storms indicate that evaporation and heat loss exert a major control, because heat loss from the water column delays the time required to attain boiling temperatures. Wind is the major parameter affecting heat loss from surface water bodies, followed by the temperature difference between water and air [Adams et al., 1990; Fournier et al., 2009; Hurwitz et al., 2012b].

In order to quantify the relative importance of changing air temperature and wind speed on the IBE for Daisy geyser, we introduce an idealized thermal model for this pool geyser. Following eruption, the geyser pool is refilled by water that is cooler than the eruption temperature. An amount of energy $U$ needs to be added to this volume in order to raise the temperature to the boiling point to permit an eruption. We further assume that this energy is provided at a rate $H$ from some deeper source, for example, as sensible and latent heat from water and steam. Energy is also lost to the atmosphere from the exposed surface of the pool by free and forced convection at a rate $A E$, where $A$ is the pool area and $E$ is the heat loss per unit area. Conservation of energy requires that

$$
U=\int_{0}^{\tau} H \mathrm{~d} t-\int_{0}^{\tau} A E \mathrm{~d} t
$$

where the integral is taken over the time from when the eruption ends, time 0 , to the beginning of the next eruption, time $\tau$. The right-hand side of equation (2) is the net input of energy needed to initiate the eruption. The energy loss from a heated pool can be calculated from the semiempirical model of Adams et al. [1990] and modified by Fournier et al. [2009]:

$$
E=\left[\left(2.7 \Delta \theta_{\mathrm{v}}^{\frac{1}{3}}\right)^{2}+\left(8.1 A^{-0.05} W_{\mathrm{s}}\right)^{2}\right]^{\frac{1}{2}}\left(e_{\mathrm{s}}-e_{\mathrm{a}}\right),
$$

where $\Delta \theta_{\mathrm{v}}$ is the virtual temperature difference between the surface water in the pool, at temperature $T_{\mathrm{p}}$, and the ambient air, at temperature $T_{\mathrm{a}}(\mathrm{K}) . W_{\mathrm{s}}$ is the wind speed $\left(\mathrm{m} \mathrm{s}^{-1}\right)$, and $e_{\mathrm{s}}-e_{\mathrm{a}}$ is the difference between the near-surface and ambient vapor pressures (in mbar). We use equations (A6) and (A5) of Fournier et al. [2009] to calculate the saturation vapor pressure as a function of temperature and the virtual temperature, using an atmospheric pressure of 0.76 bar. We assume that the pool is always close to the boiling temperature so that $e_{\mathrm{s}}-e_{\mathrm{a}} \approx e_{\mathrm{s}}$.

Over short timescales of days, the subsurface temperature, water supply, and conduit and pool geometries should remain close to constant. To assess how wind speed and ambient temperature affect an IBE over these timescales, we assume $e_{s}, A, H$, and $E$ remain constant, a reasonable approximation if the pool refills on timescales quite a bit shorter than $\tau$, the weather phenomena affecting $T_{\mathrm{a}}$ and $W_{\mathrm{s}}$ vary on timescales quite a bit longer than $\tau$, and the initial temperature in the pool is not much below the temperature at which it erupts. Equation (2) thus becomes

$$
U=(H+A E) \tau
$$

In order to predict how air temperature $T_{\mathrm{a}}$ and wind speed $W_{\mathrm{s}}$ influence the IBE, we need to know $U$ and $H$. We estimate $U$ and $H$ from the sensitivity of the IBE to wind speed shown in Figure $6 \mathrm{~b}$; as we have two unknowns, 


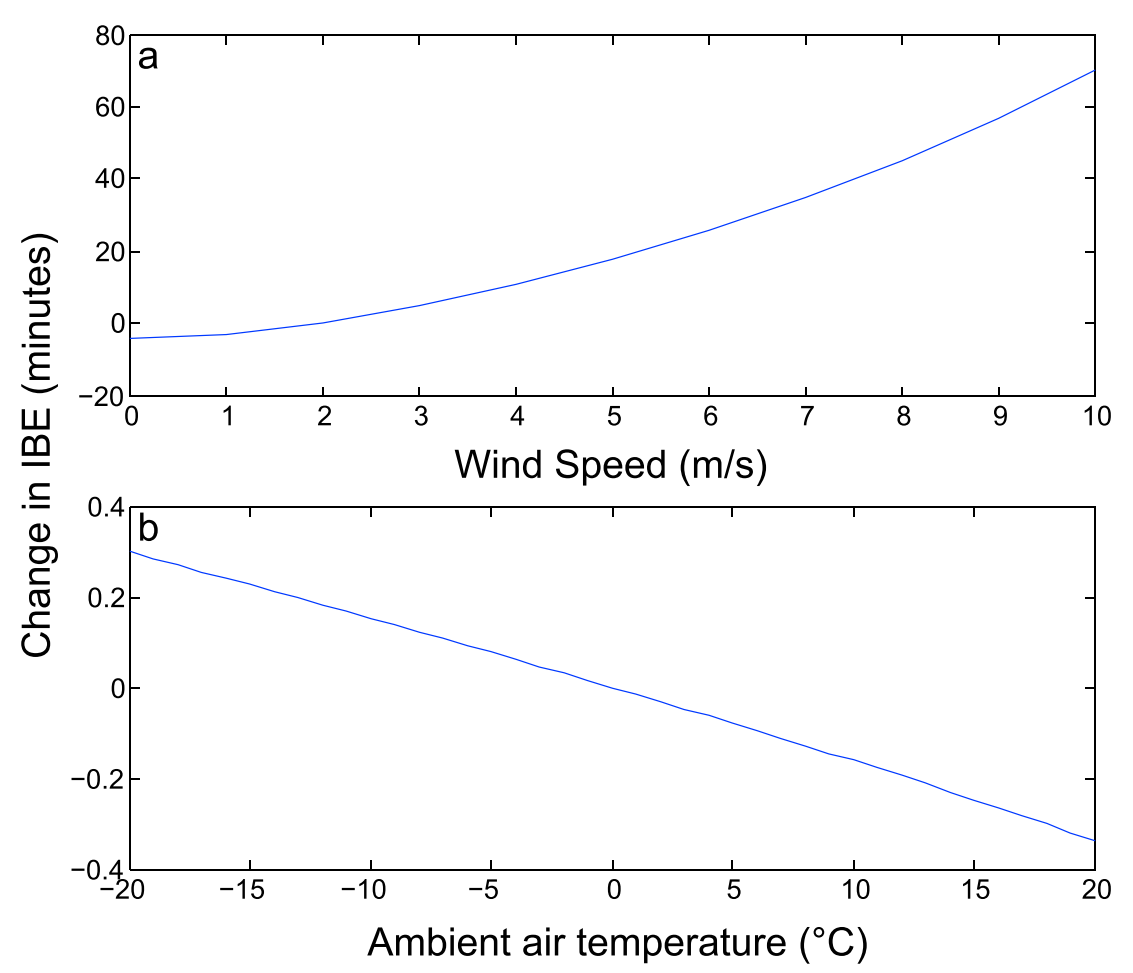

Figure 10. (a) Effect of wind speed on interval between eruption (IBE) changes, assuming a pool temperature of $90^{\circ} \mathrm{C}$, air temperature of $0^{\circ} \mathrm{C}$, and pool surface area of $10 \mathrm{~m}^{2}$. (b) Effect of changes in air temperature on changes in IBE assuming a wind speed of $2 \mathrm{~m} / \mathrm{s}$ and all other parameters the same as in Figure 10a.

we use the IBEs at two representative wind speeds, 135 and $180 \mathrm{~min}$ at $2 \mathrm{~m} / \mathrm{s}$ and $8 \mathrm{~m} / \mathrm{s}$, respectively. Because the eruption duration, a few minutes, is much less than the IBE, we equate IBE and $\tau$. We assume $T_{\mathrm{p}}=90^{\circ} \mathrm{C}$ because downhole measurements at Old Faithful indicate that the recharging fluids are close to the boiling temperature [Hutchinson et al., 1997]. Uncertainties on $A$ and $e_{\mathrm{s}}$ do not affect the results provided they remain close to constant throughout and between eruptions.

The effects of $T_{\mathrm{a}}$ and $W_{\mathrm{s}}$ on the IBE are shown in Figure 10. For the expected range of these quantities, we see a much stronger dependence on wind speed. This is apparent from the form of the evaporation equation: energy losses are linear in the wind speed (which varies by factors of several) but scales with the cube root of the temperature difference, and the virtual temperature difference varies by less than a few tens of percent. These observations of Daisy's IBE lengthening are consistent with a controlled experiment at Velikan geyser, Kamchatka, where increased surface area of the water exposed to the atmosphere, resulted in IBE lengthening, implying that cooling to the atmosphere lengthens the time required to initiate an eruption [Merzhanov et al., 1990].

\subsection{Geyser Response to Earthquakes}

We searched the IBE time series of Old Faithful and Daisy geysers for two types of IBE response to earthquakes. The first should be reflected by one or two short intervals that result from enhanced boiling while surface waves are still reverberating in the basin, and the second should be reflected by a persistent increase or decrease of the geyser's IBE for periods that are longer than the duration of teleseismic waves reverberating in the basin. Although three earthquakes were followed by Old Faithful geyser mode II intervals in the first $2 \mathrm{~h}$ after the earthquake (Figures $8 \mathrm{a}$ and $8 \mathrm{f}$ ), we cannot demonstrate that these were in response to the earthquake with statistical significance. Additionally, the postearthquake mode II intervals are not shorter than other mode II intervals, and the amplitude of the peak ground velocity following these particular three earthquakes was an order of magnitude less than the velocity following the 2002 Denali, Alaska, earthquake. These observations are further inconsistent with these short intervals being a response to the earthquakes. 

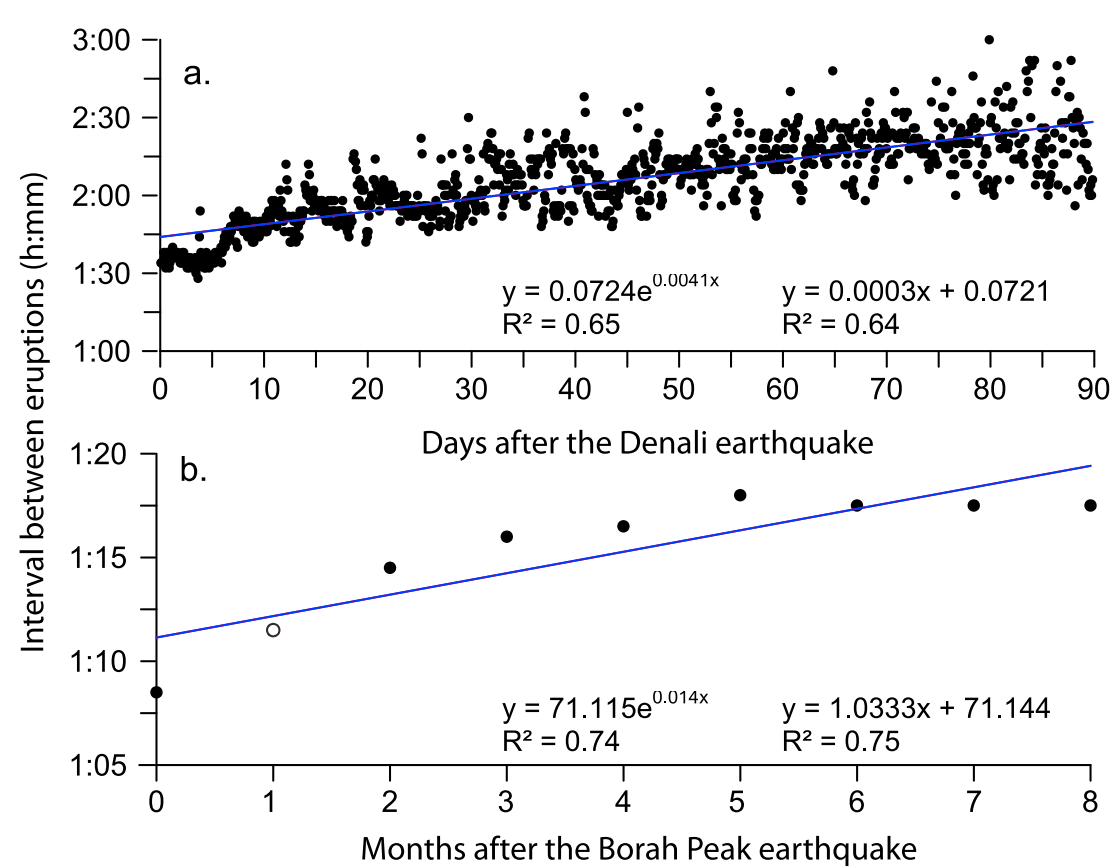

Figure 11. (a) Daisy geyser's IBEs (black symbols) in the 90 days following the November 2002 Denali, Alaska, earthquake and (b) monthly average intervals of Old Faithful geyser following the 1983 Borah Peak, Idaho, earthquake. Data were digitized from Hutchinson [1985], and the empty black circle was derived by linear extrapolation in the lack of available data. Blue and red (hidden beneath the blue) curves indicate linear and exponential fits to the data, respectively.

Based on the results described in section 4.3 , the only statistically significant geyser response to a global earthquake between 2001 and 2011 resulted in IBE shortening of Daisy geyser following the 2002 M-7.8 Denali earthquake. Eruption intervals of several other geysers in the Upper Geyser Basin also varied following the earthquake [Husen et al., 2004a]. In addition to Daisy's IBE shortening following the Denali earthquake, the IBE variance was significantly smaller than before the earthquake (Figure $8 \mathrm{~b}$ ). The IBE variance gradually increased in the weeks following the earthquake in conjunction with interval lengthening. Comparison of Daisy geyser's response to the Denali and Hebgen Lake earthquakes with Old Faithful geyser's response to the 1959 M-7.3 Hebgen Lake, 1975 M-6.1 Yellowstone NP, and the 1983 M-6.9 Borah Peak Idaho earthquake reveals that the two geysers respond to earthquakes very differently. Lengthening of Old Faithful IBEs was gradual rather than instantaneous, and the IBEs remained at a new longer IBE state (permanent change) (Figure 2). During the 10 months prior to the Borah Peak earthquake, the monthly average interval was 69-70 min, and following the earthquake, eruptions lengthened continuously until 4 months after the earthquake when the monthly average intervals were $77-78 \mathrm{~min}$ (Figure $2 \mathrm{~b}$ ). These variations are much larger than typical seasonal variations. In contrast, Daisy's IBEs returned to pre-earthquake durations following the Hebgen Lake [White and Marler, 1972] and Denali earthquakes. White and Marler [1972, p. 5829] described the effects of the 1959 Hebgen Lake earthquake on geysers "The major effect of seismic shaking evidently was to increase the dimensions of most channels of discharge and to create some new channels from this overpressured system, but Old Faithful's plumbing system was one of the very few that was not directly changed". The contrasting responses of Old Faithful and Daisy geysers to earthquakes support the notion that "Geysers are exceedingly complex hot springs, no two of which are alike" [White and Marler, 1972, p. 5825] and that there is no "characteristic" geyser response.

These different types of geyser response are similar to the variability observed for documented hydrologic responses to earthquakes that include changes in water level in wells and discharge variations in springs, streams, and mud volcanoes [e.g., Mogi et al., 1989; Rojstaczer et al., 1995; Roeloffs, 1998; Brodsky et al., 2003; Montgomery and Manga, 2003; Matsumoto and Roeloffs, 2003; Elkhoury et al., 2006, 2011; Doan and Cornet, 2007; Geballe et al., 2011; Rudolph and Manga, 2010, 2012; Niwa et al., 2012]. The mechanism(s) accounting for the recovery is (are) not well understood but is (are) typically attributed to permeability changes that result from mechanical and/or chemical processes that alter fluid pathways perturbed by the seismic shaking 
Table 1. Seismic Energy Density $(\varepsilon)$ and Calculated Stresses From Regional and Teleseismic Earthquakes in Yellowstone

\begin{tabular}{|c|c|c|c|c|c|c|c|}
\hline Earthquake & Year & Magnitude & Distance (km) & $\log \varepsilon$ & Static Stress (MPa) & Dynamic Stress (MPa) & Source \\
\hline Hebgen Lake & 1959 & 7.3 & 48 & 1.28 & $0.2-0.3$ & $(-)$ & [Chang and Smith, 2002] \\
\hline Yellowstone & 1975 & 6.1 & 34 & -0.01 & $(-)$ & $(-)$ & \\
\hline Borah Peak & 1983 & 6.9 & 240 & -1.42 & $\gg 0.01$ & $\sim 0.5$ & $\begin{array}{c}\text { [Chang and Smith, 2002; Payne et al., } \\
\text { 2004; Rojstaczer et al., 2003] }\end{array}$ \\
\hline Denali & 2002 & 7.7 & 3134 & -3.98 & $(-)$ & $0.14-0.22$ & $\begin{array}{l}\text { [Velasco et al., 2004; Husen et al., } \\
\text { 2004a]; this study }\end{array}$ \\
\hline Northern California & 2005 & 7.2 & 1244 & -3.15 & $(-)$ & 0.02 & This study \\
\hline Maule & 2010 & 8.8 & 9742 & -3.53 & $(-)$ & 0.02 & This study \\
\hline Tohoku & 2011 & 9.1 & 8251 & -3.31 & $(-)$ & 0.01 & This study \\
\hline
\end{tabular}

during the earthquake [Manga and Wang, 2007; Manga et al., 2012]. Documented recovery times range from 3 min to 6 years [Manga et al., 2012], and they can be approximately exponential [e.g., Brodsky et al., 2003; Doan and Cornet, 2007; Geballe et al., 2011] or linear [e.g., Elkhoury et al., 2006].

The post-Denali IBE recovery of Daisy can be matched with either a linear or an exponential curve (Figure 11a). There are no constraints on the controlling parameters needed to determine the possible processes controlling post-earthquake IBE recovery. Further, Daisy geyser's response to earthquakes and its recovery are complex because its intervals can be altered by interaction with neighboring geysers (Splendid, Bonita, Comet, and Daisy's Thief in the past) [Bryan, 1995]. In fact, except for two eruptions in 1968, Daisy was dormant between 1960 and 1971, when the neighboring geysers were active and Bonita pool was overflowing [Bryan, 1995]. When Daisy resumed eruptions in 1971, activity in the neighboring geysers and overflow from Bonita Pool decreased. Thus, the gradual decrease of Daisy's IBEs in the day following the passage of seismic waves from Denali could be associated with water level variations in Bonita Pool, but such observations were not made. We obtained the post-October 1983 Borah Peak, Idaho, monthly average IBE by digitizing a graph in Hutchinson [1985]. The average IBE for November is not available, so the value was obtained by linear interpolation (Figure 11b). The gradual IBE increase during the first 8 months is equally fit with linear or exponential curves. Thus, the processes that control the gradual recovery of both geysers are not well constrained.

Models proposed to explain hydrologic response to large regional or remote earthquakes highlight the differences in the response to earthquakes that induce large static stress changes (at distances within approximately one fault length) compared with the response to surface waves that induce much larger dynamic stresses (at distances up to several thousand kilometers). To estimate the magnitude of the stresses that have led to a measurable geyser IBE response, we compare the calculated static stress changes in the Upper Geyser Basin following the Hebgen Lake earthquake centered $44 \mathrm{~km}$ to the northwest (0.2-0.3 MPa), and the calculated stress changes induced by the Borah Peak earthquake centered $240 \mathrm{~km}$ west-southwest of Old Faithful («0.1 MPa) [Chang and Smith, 2002; Payne et al., 2004] with dynamic shear stresses associated with crustal surface waves with 15-30 s periods [Hill, 2012] induced by remote earthquakes (Table 1). Following the approach of Hill et al. [1993] and Velasco et al. [2004], we calculate peak dynamic stress (PDS) induced by the surface waves of the M-9.1 Tohoku-Oki, Japan, earthquake; the June 2005 M-7.2 Northern California earthquake; and the November 2002 M-7.8 Denali, Alaska, earthquake:

$$
\mathrm{PDS}=\bar{v} \frac{\mu}{\beta}
$$

where $\bar{v}$ is the peak vector velocity, $\mu$ is the shear modulus, and $\beta$ is the shear wave velocity. We measured peak velocity recorded on broadband station LKWY near Yellowstone Lake (Figure 1) and follow Velasco et al. [2004] in using a shear modulus of $\mu=33 \mathrm{GPa}$ and a shear wave velocity of $\beta=3500 \mathrm{~m} / \mathrm{s}$. The PDS induced by the Denali earthquake is $0.14 \mathrm{MPa}$ at LKWY (Figure 12a), which is slightly lower than determined by other studies, 0.16-0.22 MPa [Husen et al., 2004a, 2004b; Velasco et al., 2004]. However, using data from station LKWY (Figure 1), we find that the PDS induced by the Denali earthquake is an order of magnitude greater than the PDS induced by the Tohoku-Oki earthquake (0.01 MPa) (Table 1). The large amplitude of the Denali earthquake surface waves was attributed to the directivity of the waves, which were optimally oriented toward the Rocky Mountains [Velasco et al., 2004]. Other large remote earthquakes induced PDSs that are at least one order of magnitude smaller than the PDS induced by the Denali earthquake (Figures 12b-12d). 


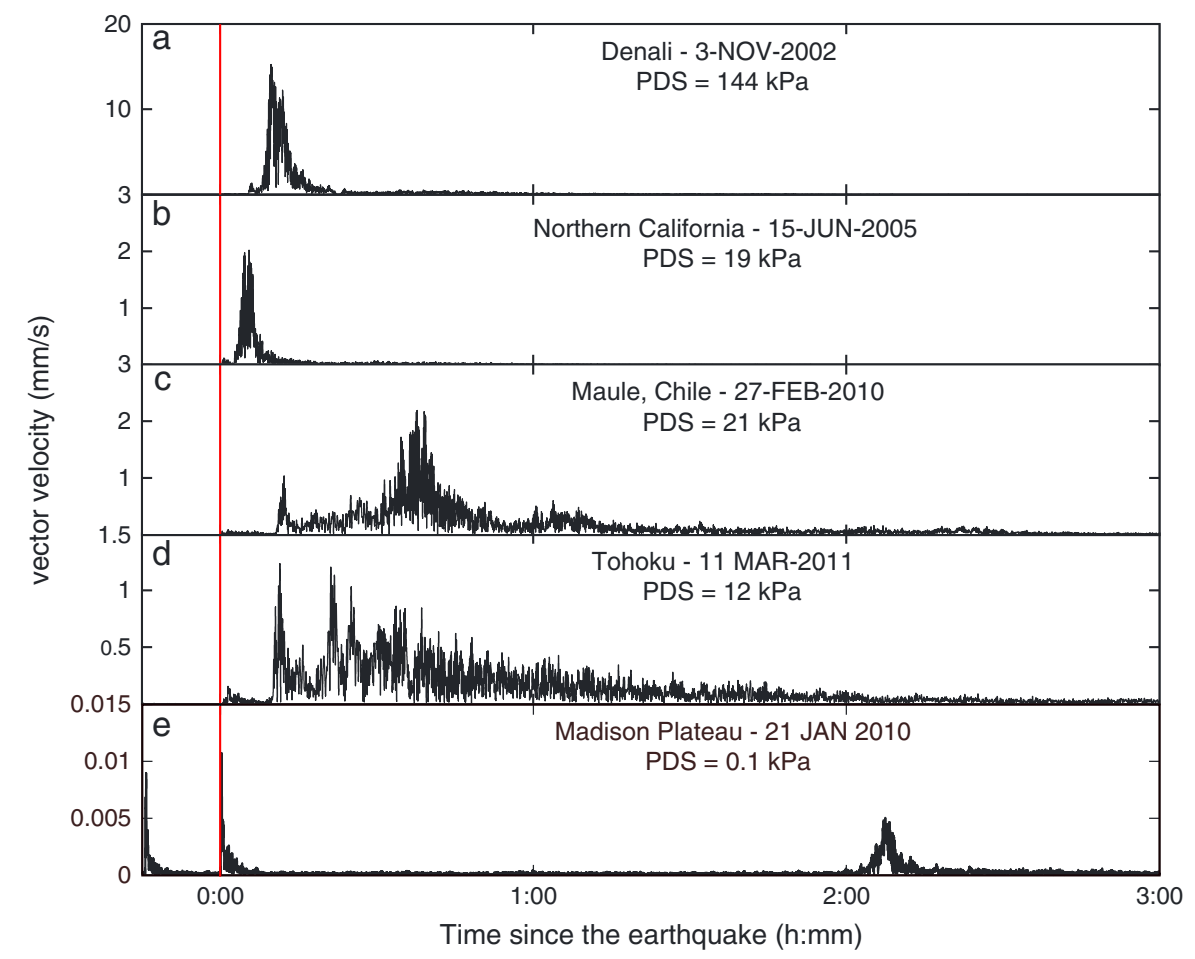

Figure 12. Calculated ground velocity in Yellowstone induced by the (a) November $2002 M 7.8$ Denali earthquake, (b) June 2005 M 7.2 Northern California earthquake, (c) February 2010 M 8.8 Maule Chile earthquake, (d) March 2011 M 9.1 Tohoku earthquake, and (e) January 2010 M 4.2 earthquake in the Madison Plateau, Yellowstone National Park. The waveforms used for the calculations are from seismic station H17A (Figure 1). The vertical red line marks the theoretical arrival time of $P$ waves. Peak dynamic stress (PDS) are calculated using equation (3). The waveforms used for the calculations are from seismic station LKWY (Figure 1).

Unfortunately, during the Borah Peak earthquake, the Yellowstone seismic network was not operational. However, based on ground velocities from the M 7.3 1992 Landers, California, and the distance between earthquake source to the Upper Geyser Basin, Rojstaczer et al. [2003] calculated dynamic shear stress changes on the order of $0.5 \mathrm{MPa}$, significantly greater than the static stress changes (Table 1), suggesting that the gradual IBE increase was in response to dynamic stress changes from the long-period seismic waves.

Overall, Old Faithful IBEs did not vary, but the IBEs of Daisy and several other geysers in Yellowstone did vary in response to dynamic stress changes of 0.1-0.2 MPa. The IBEs of Old Faithful did vary in response to dynamic stress changes on the order of $0.5 \mathrm{MPa}$ induced by the Borah Peak earthquake (Table 1). A possible explanation for the efficiency of dynamic stresses to modulate hydrothermal activity is the sensitivity of systems with high fluid pressure to long-period seismic waves [Hill, 2012]. In Yellowstone's geyser basins, the fluid pressure gradient in the upper $200 \mathrm{~m}$ is $\sim 130 \%$ of the hydrostatic gradient, and temperatures through this high-gradient zone are close to boiling at the corresponding pressures [White and Marler, 1972; White et al., 1975]. This inference is consistent with a study that demonstrated that mud volcanoes in Southern California are more sensitive to long-period seismic waves than to shorter-period waves of the same amplitude [Rudolph and Manga, 2012]; a study that showed that following the 2002 Denali earthquake, the long-period seismic waves triggered seismicity at Long Valley Caldera in Eastern California, while highfrequency seismic waves with comparable cumulative seismic energy density did not [Brodsky and Prejean, 2005]; and a study that showed enhanced triggering of earthquakes at fluid-injection sites in the midwestern United States by long-period seismic waves induced by large remote earthquakes [van der Elst et al., 2013]. The sensitivity of hydrothermal systems to long-period seismic waves might also be evident in the lack of observable geyser response to the earthquakes in the 2010 Madison Plateau earthquake swarm that produced large seismic energy density $(\varepsilon)$ in the Upper Geyser Basin (Figure 9) but did not generate longperiod seismic waves. The high-frequency waves generated peak PDS of only $0.1 \mathrm{kPa}$ (Figure 12e). 


\section{Conclusions}

Based on the statistical analysis of Old Faithful and Daisy geysers intervals between eruptions (IBEs) for the period between 2001 and 2011 and the response of Old Faithful geyser to three large regional earthquakes in 1959, 1975, and 1984, we conclude the following:

1. Old Faithful and Daisy geysers are insensitive to periodic stresses induced by solid earth tides and barometric pressure variations.

2. The eruption intervals of Daisy geyser (pool geyser) lengthen during large wind storms by evaporation and heat loss, which results in a longer time required to reach the boiling temperature.

3. Diurnal variations of Daisy geyser (pool geyser) eruption intervals are modulated by air temperature variations and evaporation. The IBEs of Old Faithful geyser are not modulated by air temperature and pressure variations, wind storms (evaporation), and precipitation. This suggests that in Old Faithful (cone geyser) the subsurface water column is thermally decoupled from the atmosphere and that the relatively small volume of water in the conduit does not exert a major control on the eruption.

4. Several geysers in Yellowstone responded to dynamic stresses of 0.2-0.3 MPa induced by surface waves from the 2002 M-7.9 Denali earthquake, but the IBEs of other geysers including Old Faithful geyser did not vary. No geyser responded to dynamic stresses $<0.02 \mathrm{MPa}$ induced by global earthquakes with magnitudes of up to 9.1 (Tohoko-Oki earthquake in Japan).

5. Three remote earthquakes were followed by mode II eruption intervals ( $<75 \mathrm{~min}$ ) of Old Faithful geyser within $2 \mathrm{~h}$ of the earthquake when the surface waves were still reverberating in the basin. However, these short intervals are probably not in response to the earthquakes.

6. The eruption intervals of Old Faithful geyser increased in response to three regional earthquakes. Permanent interval lengthening following the Borah Peak earthquake was in response to dynamic stresses on the order of $0.5 \mathrm{MPa}$.

7. Our analyses suggest that the response to external forces is relatively small, implying that most of the geyser IBE variability is dominated by some combination of internal processes and interaction with other geysers [Bloss and Barth, 1949; Marler, 1951; Rojstaczer et al., 2003].

Acknowledgments

We are grateful to Ralph Taylor and the Geyser Observation Society of America (GOSA) for developing and maintaining the geyser monitoring systems in Yellowstone National Park and for making the data available. Fred Murphy helped with the compilation of the weather data. K. Luttrell and S. Hurwitz were supported by the USGS Volcano Hazards Program, and Michael Manga was supported by NSF grant

EAR1114184. Constructive comments and reviews by Alexander Belousov, Wu-Lung Chang, Bob Fournier, Malcolm Johnston, and Mike Poland helped improve the quality of this paper.

\section{References}

Adams, E., D. Cosler, and K. Helfrich (1990), Evaporation from heated water bodies: Predicting combined forced plus free convection, Water Resour. Res., 26, 425-435, doi:10.1029/WR026i003p00425.

Agnew, D. C. (2007), Earth tides, in: Treatise on Geophysics: Geodesy, 163-195, New York, Elsevier.

Agnew, D. C. (2012), SPOTL: Some Programs for Ocean-Tide Loading, Scripps Institution of Oceanography Technical Report. [Available at http:// escholarship.org/uc/item/954322pg.]

Alam, M., and M. Kimura (2004), Statistical analysis of time-distance relationship between volcanic eruptions and great earthquakes in Japan, Earth Planet. Space, 56, 179-192.

Allen, E. T., and A. L. Day (1935), Hot springs of the Yellowstone National Park, Carnegie Inst. Washington Publ., $466,525$.

Azzalini, A., and A. W. Bowman (1990), A look at some data on the Old Faithful geyser. Appl. Stat., 39, 357-365.

Beeler, N. M., and D. A. Lockner (2003), Why earthquakes correlate weakly with the solid Earth tides: Effects of periodic stress on the rate and probability of earthquake occurrence, J. Geophys. Res., 108(B8), 2391, doi:10.1029/2001JB001518.

Belousov, A., M. Belousova, and A. Nechayev (2013), Video observations inside conduits of erupting geysers in Kamchatka, Russia, and their geological framework: Implications for the geyser mechanism, Geology, 41, 387-390, doi:10.1130/G33366.1.

Bloss, F. D., and T. F. W. Barth (1949), Observations on some Yellowstone geysers, Geol. Soc. Amer. Bull., 60, 861-886.

Bower, G. R. (1994), Daisy Geyser: Possible causes of variation in activity, GOSA Transac., 5, 43-61.

Bredehoeft, J. D. (1967), Response of well-aquifer systems to Earth tides, J. Geophys. Res., 72, 3075-3087, doi:10.1029/JZ072i012p03075.

Brillinger, D. R. (1975), Statistical inference for stationary point processes, in Proceedings of the Summer Research Institute on Statistical Inference for Stochastic Processes, vol. 1, edited by M. L. Puri, pp. 55-99, Academic Press, New York.

Brodsky, E. E., and S. G. Prejean (2005), New constraints on mechanisms of remotely triggered seismicity at Long Valley Caldera, J. Geophys. Res., 110, B04302, doi:10.1029/2004JB003211.

Brodsky, E. E., E. Roeloffs, D. Woodcock, I. Gall, and M. Manga (2003), A mechanism for sustained groundwater pressure changes induced by distant earthquakes, J. Geophys. Res., 108(B8), 2390, doi:10.1029/2002JB002321.

Bryan, T. S. (1995), The Geysers of Yellowstone, 463 pp., Univ. Press of Colorado, Boulder, Colo.

Chang, W.-L., and R. B. Smith (2002), Integrated seismic-hazard analysis of the Wasatch Front, Utah, Bull. Seismol. Soc. Am., 92, 1904-1922, doi:10.1785/0120010181.

Chesley, C., P. C. LaFemina, C. Puskas, and D. Kobayashi (2012), The $1707 \mathrm{M}_{\mathrm{w}} 8.7$ Hoei earthquake triggered the largest historical eruption of Mt. Fuji, Geophys. Res. Lett., 39, L24309, doi:10.1029/2012GL053868.

Doan, M. L., and F. H. Cornet (2007), Small pressure drop triggered near a fault by small teleseismic waves, Earth Planet. Sci. Lett., 258, 207-218, doi:10.1016/j.epsl.2007.03.03.

Doser, D. I. (1985), Source parameters and faulting processes of the 1959 Hebgen Lake, Montana, earthquake sequence, J. Geophys. Res., 90 , 4537-4555, doi:10.1029/JB090iB06p04537. 
Dzurisin, D. (1980), Influence of fortnightly Earth tides at Kilauea volcano, Hawaii, Geophys. Res. Lett., 7, 925-928, doi:10.1029/GL007i01 1 p00925. Eggert, S., and T. R. Walter (2009), Volcanic activity before and after large tectonic earthquakes: Observations and statistical significance, Tectonophysics, 471, 14-26, doi:10.1016/j.tecto.2008.10.003.

Elkhoury, J. E., E. E. Brodsky, and D. C. Agnew (2006), Seismic waves increase permeability, Nature 441, 1135-1138, doi:10.1038/nature04798.

Elkhoury, J. E., A. Niemeijer, E. E. Brodsky, and C. Marone (2011), Laboratory observations of permeability enhancement by fluid pressure oscillation of in situ fractured rock, J. Geophys. Res., 116, B02311, doi:10.1029/2010JB007759.

Emter, D. (1997), Tidal triggering of earthquakes and volcanic events, in Tidal Phenomena, edited by H. Wilhelm, W. Zurm, and H.-G. Wenzel, pp. 295-309, Springer, New York.

Fournier, R. O. (1969), Old Faithful: A physical model, Science, 163, 304-305.

Fournier N., F. Witham, M. Moreau-Fournier, and L. Bardou (2009) Boiling Lake of Dominica, West Indies: High-temperature volcanic crater lake dynamics, J. Geophys. Res., 114, B02203, doi:10.1029/2008JB005773.

Geballe, Z. M., C.-Y. Wang, and M. Manga (2011), A permeability-change model for water level changes triggered by teleseismic waves, Geofluids, 11, 302-308, doi:10.1111/j.1468-8123.2011.00341.x.

Golombek, M. P., and M. J. Carr (1978), Tidal triggering of seismic and volcanic phenomena during the 1879-1880 eruption of Islas Quemadas volcano in El Salvador, Central America. J. Volcanol. Geotherm. Res., 3, 299-307.

Hamilton, W. L. (1973), Tidal cycles of volcanic eruptions: Fortnightly to 19 yearly periods, J. Geophys. Res., 78, 3356-3375, doi:10.1029/ JB078i017p03363.

Hill, D. P. (2012), Dynamic stresses, Coulomb failure, and remote triggering_Corrected, Bull. Seismol. Soc. Am., 102, 2313-2336.

Hill, D. P., et al. (1993), Seismicity in the western United States remotely triggered by the M 7.4 Landers, California, earthquake of June 28 , 1992, Science, 260, 1617-1623.

Hsieh, P. A., J. D. Bredehoeft, and S. A. Rojstaczer (1988), Response of well aquifer systems to earth tides: Problem revisited, Water Resour. Res., 24, 468-472, doi:10.1029/WR024i003p00468.

Hurwitz, S., A. Kumar, R. Taylor, and H. Heasler (2008), Climate-induced variations of geyser periodicity in Yellowstone National Park, USA, Geology, 36, 451-454, doi:10.1130/G24723A.1.

Hurwitz, S., A. G. Hunt, and W. C. Evans (2012a), Temporal variations of geyser water chemistry in the Upper Geyser Basin, Yellowstone National Park, USA, Geochem. Geophys. Geosyst., 13, Q12005, doi:10.1029/2012GC004388.

Hurwitz, S., R. N., Harris, C. A., Werner, F., Murphy (2012b), Heat flow in vapor dominated areas of the Yellowstone Plateau Volcanic Field: Implications for the thermal budget of the Yellowstone Caldera, J. Geophys. Res., 117, B10207, doi:10.1029/2012JB009463.

Husen, S., R. Taylor, R. B. Smith, and H. Healser (2004a), Changes in geyser eruption behavior and remotely triggered seismicity in Yellowstone National Park produced by the 2002 M 7.9 Denali Fault earthquake, Alaska, Geology, 32, 537-540, doi:10.1130/G20381.1.

Husen, S., S. Wiemer, and R. B. Smith (2004b), Remotely triggered seismicity in the Yellowstone National Park region by the $2002 \mathrm{Mw} 7.9$ Denali Fault earthquake, Alaska, Bull. Seismol. Soc. Am., 94, S317-S331.

Hutchinson, R. A. (1985), Hydrothermal changes in the Upper Geyser Basin, Yellowstone National Park, after the 1983 Borah Peak, Idaho, earthquake, U.S. Geol. Surv. Open File Rep., 85-290, 612-624.

Hutchinson, R. A., J. A. Westphal, and S. W. Kieffer (1997), In situ observations of Old Faithful Geyser, Geology, 25, 875-878.

Hyndman, R. J. (1996), Computing and graphing highest density regions, Amer. Stat., 50, 120-126.

Ingebritsen, S. E., and S. A. Rojstaczer (1993), Controls on geyser periodicity, Science, 262, 889-892.

Ingebritsen, S. E., and S. A. Rojstaczer (1996), Geyser periodicity and the response of geysers to small strains in the Earth, J. Geophys. Res., 101, 21,891-21,907, doi:10.1029/96JB02285.

Johnston, M. J. S., and F. J. Mauk (1972), Earth tides and the triggering of eruptions from Mount Stromboli, Italy, Nature, 239, 266-267.

Karlstrom, L., S. Hurwitz, R. A. Sohn, J. Vandemeulebrouck, F. Murphy, M. L. Rudolph, M. J. S. Johnston, M. Manga, and R. B. McCleskey (2013) Eruptions at Lone Star Geyser, Yellowstone National Park, USA, Part 1: Energetics and eruption dynamics, J. Geophys. Res. Solid Earth, 118, 1-15, doi:10.1002/jgrb.50251.

Kedar, S., H. Kanamori, and B. Sturtevant (1998), Bubble collapse as the source of harmonic tremor at Old Faithful Geyser, J. Geophys. Res., 103, 24,283-224,299, doi:10.1029/98JB01824.

Kieffer, S. W. (1984), Seismicity at Old Faithful Geyser: An isolated source of geothermal noise and possible analogue of volcanic seismicity, J. Volcanol. Geotherm. Res., 22, 59-95.

Kieffer, S. W. (1989), Geologic nozzles, Rev. Geophys, 27, 3-38, doi:10.1029/RG027i001p00003.

Kiryukhin, A. V., T. V. Rychkova, and I. K. Dubrovskaya (2012), Formation of the hydrothermal system in Geysers Valley (Kronotsky Nature Reserve, Kamchatka) and triggers of the Giant Landslide, Appl. Geochem., 27, 1753-1766, doi:10.1016/j.apgeochem.2012.02.011.

Kottas, A. and G. W. Fellingham (2012), Bayesian semiparametric modeling and inference with mixtures of symmetric distributions, Stat. Comput., 22, 93-106, doi:10.1007/s11222-010-9208-x.

Langford, N. P. (1905), Diary of the Washburn Expedition to the Yellowstone and Firehole Rivers in the Year 1870, 122 pp., J.E. Haynes, St. Paul, Minnesota.

Langrock, R. (2012), Flexible latent-state modelling of Old Faithful's eruption inter-arrival times in 2009, Austr. New Zeal. J. Stat., 54, 261-279.

Linde, A. T., and I.S. Sacks (1998), Triggering of volcanic eruptions. Nature 395, 888-490.

Llewellin, E. and M. Manga (2005) Bubble suspension rheology and implications for conduit flow, J. Volcanol. Geotherm. Res., 143, 205-217.

Lockner, D. A., and N. M. Beeler (1999), Premonitory slip and tidal triggering of earthquakes, J. Geophys. Res., 104, 20,133-20,151, doi:10.1029/ 1999JB900205.

Luttrell, K., D. Mencin, O. Francis, and S. Hurwitz (2013), Constraints on the upper crustal magma reservoir beneath Yellowstone Caldera inferred from lake-seiche induced strain observations, Geophys. Res. Lett., 40, 501-506, doi:10.1002/grl.50155.

Manga, M., and E. Brodsky (2006), Seismic triggering of eruptions in the far field: Volcanoes and geysers, Ann. Rev. Earth Planet. Sci, 34, $263-291$.

Manga, M., and C.-Y. Wang (2007), Earthquake hydrology, in Treatise on Geophysics, edited by G. Schubert, vol. 4, pp. 293-320, Amsterdam, Netherlands.

Manga, M., I. Beresnev, E. E. Brodsky, J. E. Elkhoury, D. Elsworth, S. E. Ingebritsen, D. C. Mays, and C.-Y. Wang (2012), Changes in permeability caused by transient stresses: Field observations, experiments, and mechanisms, Rev. Geophys., 50, RG2004, doi:10.1029/2011RG000382.

Marler, G. D. (1951), Exchange of function as a cause of geyser irregularity [Wyoming], Am. J. Sci, 249, 329-342, doi:10.2475/ajs.249.5.329.

Marler, G. D. (1964), Effects of the Hebgen Lake earthquake of August 17, 1959 on the hot springs of the Firehole geyser basins, Yellowstone National Park, U.S. Geol. Surv. Prof. Pap., 435, 185.

Marler, G. D., and D. E. White (1975), Seismic Geyser and its bearing on the origin and evolution of geysers and hot springs of Yellowstone National Park, Geol. Soc. Am. Bull., 86, 749-759. 
Martin, D. P., and W. I. Rose (1981), Behavioral patterns of Fuego volcano, Guatemala, J. Volcanol. Geotherm. Res., $10,67-81$.

Mason, B., D. M. Pyle, W. B. Dade, and T. Jupp (2004), Seasonality of volcanic eruptions. J. Geophys. Res., 109, B04206, doi:10.1029/ 2002JB002293.

Mastin, L. G. (1994), Explosive tephra emissions of Mount St. Helens, 1989-1991: The violent escape of magmatic gas following storms?, Geol. Soc. Am. Bull., 106, 175-185.

Matsumoto, N., and E. A. Roeloffs (2003), Hydrological response to earthquakes in the Haibara well, central Japan-II. Possible mechanism inferred from time-varying hydraulic properties, Geophys. J. Inter., 155, 899-913.

Matthews, A. J., J. Barclay, S. Carn, G. Thompson, J. Alexander, R. Herd, and C. Williams (2002), Rainfall-induced volcanic activity on Montserrat, Geophys. Res. Lett., 29(13), 1644, doi:10.1029/2002GL014863.

Mauk, F. J., and M. J. S. Johnston (1973), On the triggering of volcanic eruptions by Earth tides, J. Geophys. Res., 78, 3356-3362.

Merzhanov, A. G., A. S. Shteinberg, and G. S. Shteinberg (1990), Heat and mass exchange in geyser systems, in Proceedings of the 9th International Heat Transfer Conference, edited by G. Hestroni, pp. 323-328.

Mogi, K., H. Mochizuki, and Y. Kurokawa (1989), Temperature changes in an artesian spring at Usami in the Izu Peninsula (Japan) and their relation to earthquakes, Tectonophysics, 159, 95-108.

Montgomery, D. R., and M. Manga (2003), Streamflow and water well responses to earthquakes, Science, 300, $2047-49$.

Neuberg, J. (2000), External modulation of volcanic activity, Geophys. J. Int., 142, 232-240.

Nicholl, M. J., S. W. Wheatcraft, and S. W. Tyler (1994), Is Old Faithful a strange attractor?, J. Geophys. Res., 99, 4495-4503.

Niwa, M., R. Takeuchi, H. Onoe, K. Tsuyuguchi, K. Asamori, K. Umeda, and K. Sugihara (2012), Groundwater pressure changes in Central Japan induced by the 2011 off the Pacific coast of Tohoku Earthquake, Geochem. Geophys. Geosyst., 13, Q05020, doi:10.1029/2012GC004052.

O'Hara, K. D., and E. K. Esawi (2013). Model for the eruption of the Old Faithful geyser, Yellowstone National Park, GSA Today, 23, 4-9.

Patanè, G., A. Frasca, A. Agodi, and S. Imposa (1994), Earth tides and Etnean volcanic eruptions: An attempt at correlation of the two phenomena during the 1983, 1985 and 1986 eruptions, Phys. Earth Planet. Inter., 87, 123-135.

Payne, S. J., J. E. Zollweg, and D. W. Rodgers (2004), Stress triggering of conjugate normal faulting: Late aftershocks of the 1983 Ms 7.3 Borah Peak, Idaho, earthquake, Bull. Seismol. Soc. Am., 94, 828-844.

Percival, D. B., and A. T. Walden (1993), Spectral Analysis for Physical Applications, Cambridge Univ. Press, Cambridge, England.

Pitt, A. M., C. S. Weaver, and W. Spence (1979), The Yellowstone Park Earthquake of June 30, 1975, Bull. Seismol. Soc. Am., 69, 187-205.

Rinehart, J. S. (1969), Old Faithful geyser performance 1870 to 1966, Bull. Volcanol., 33, 153-163.

Rinehart, J. S. (1972a), Fluctuations in geyser activity caused by variations in earth tidal forces, barometric pressure, and tectonic stresses, J. Geophys. Res., 77, 342-350.

Rinehart, J. S. (1972b), Reply to "Comments on paper by John S. Rinehart, 'Fluctuations in geyser activity caused by earth tidal forces, barometric pressure, and tectonic stresses", J. Geophys. Res., 77, 5830-5831.

Rinehart, J. S. (1980), Geysers and Geothermal Energy, Springer-Verlag, New York.

Rinehart, J. S., and A. Murphy (1969), Observations on pre- and post-earthquake performance of Old Faithful geyser, J. Geophys. Res., 74 , 574-575.

Roeloffs, E. (1996), Poroelastic techniques in the study of earthquake-related hydrologic phenomena, Adv. Geophys., 38, $135-195$.

Roeloffs, E. A. (1998), Persistent water level changes in a well near Parkfield, California, due to local and distant earthquakes, J. Geophys. Res. 103, 869-889, doi:10.1029/97JB02335.

Rojstaczer, S., S. Wolf, and R. Michel (1995), Permeability enhancement in the shallow crust as a cause of earthquake-induced hydrological changes, Nature, 373, 237-239.

Rojstaczer, S., D. L. Galloway, S. E. Ingebritsen, and D. M. Rubin (2003), Variability in geyser eruptive timing and its causes: Yellowstone National Park, Geophys. Res. Lett., 30(18), 4, doi:10.1029/2003GL017853.

Rudolph, M. L., and M. Manga (2010) Mud volcano response to the April 4, 2010 El Mayor-Cucapah earthquake, J. Geophys. Res., 115, B12211, doi:10.1029/2010JB007737.

Rudolph, M., and M. Manga (2012) Frequency dependence of mud volcano response to earthquakes, Geophys. Res. Lett., 39, L14303, doi:10.1029/2012GL052383.

Rudolph, M. L., M. Manga, S. Hurwitz, M. J. Johnston, L. Karlstrom, and C.-Y. Wang (2012), Mechanics of old faithful Geyser, Calistoga, California, Geophys. Res. Lett., 39, L24308, doi:10.1029/2012GL054012.

Saar M. O., M. Manga, K. V. Cashman, and S. Fremouw (2001), Numerical models of the onset of yield strength in crystal-melt suspensions. Earth Planet. Sci. Lett., 187, 367-79.

Selva, J., W. Marzocchi, F. Zencher, E. Casarotti, A. Piersanti, and E. Boschi (2004), A forward test for interaction between remote earthquakes and volcanic eruptions: The case of Sumatra (June 2000) and Denali (November 2002) earthquakes, Earth Planet. Sci. Lett., 226, $383-95$.

Shelly, D. R., D. P. Hill, F. Massin, J. Farrell, and R. B. Smith (2013), A fluid-driven earthquake swarm on the margin of the Yellowstone Caldera, J. Geophys. Res. Solid Earth, 118, 4872-4886, doi:10.1002/jgrb.50362.

Shteinberg, A., M. Manga, and E. Korolev (2013), Measuring pressure in the source region for geysers, Geyser Valley, Kamchatka, J. Volcanol. Geotherm. Res., 264, 12-16.

Sparks, R. S. J. (1981), Triggering of volcanic eruptions by Earth tides, Nature, 290, 448.

Steinberg, G. S., A. G. Merzhanov, and A. S. Steinberg (1982), Geyser process: Its theory, modeling and field experiment. Part 4. On seismic influence on geyser regime, Mod. Geol., 8, 79-86.

Stephens, L. (2002), Old Faithful Geyser's lengthening intervals, GOSA Transac., 7, 5-24.

Thomson, D. (1982), Spectrum estimation and harmonic analysis, Proc. IEEE, 70, 1055-1096.

Vandemeulebrouck, J., P. Roux, and E. Cros (2013), The plumbing of Old Faithful Geyser revealed by hydrothermal tremor, Geophys. Res. Lett., 40, 1989-1993, doi:10.1002/grl.50422.

van der Elst, N. J., H. M. Savage, K. M. Keranen, and G. A. Abers (2013), Enhanced remote earthquake triggering at fluid-injection sites in the midwestern United States, Science, 341, 164-167, doi:10.1126/science.1238948.

Velasco, A. A., C. J. Ammon, J. Farrell, and K. Pankow (2004), Rupture directivity of the 3 November 2002 Denali Fault earthquake determined from surface waves, Bull. Seismol. Soc. Am., 94, S293-S299.

Walsh, S. D. C., and M. O. Saar (2008), Magma yield stress and permeability: Insights from multiphase percolation theory, J. Volcanol. Geotherm. Res., 177, 1011-1019, doi:10.1016/j.jvolgeores.2008.07.009.

Walter, T. R. (2007), How a tectonic earthquake may wake up volcanoes: Stress transfer during the 1996 earthquake-eruption sequence at the Karymsky Volcanic Group, Kamchatka, Earth Planet. Sci. Lett., 264, 347-359, doi:10.1016/j.epsl.2007.09.006.

Walter, T. R., and F. Amelung (2007), Volcanic eruptions following M > 9 megathrust earthquakes: Implications for the Sumatra-Andaman volcanoes, Geology, 35, 539-542, doi:10.1130/G23429A.1. 
Wang, C.-Y., and Y. Chia (2008), Mechanism of water level changes during earthquakes: Near field versus intermediate field, Geophys. Res. Lett., 35, L12402, doi:10.1029/2008GL034227.

Weir, G. J., R. M. Young, and P. N. McGavin (1992), A simple model for Geyser Flat, Whakarewarewa, Geothermal, 21, 281-304.

White, D. E. (1967), Some principles of geyser activity, mainly from Steamboat Springs, Nevada, Am. J. Sci., 265, 641-684.

White, D. E., and G. D. Marler (1972), Comments on paper by John S. Rinehart, 'Fluctuations in geyser activity caused by earth tidal forces, barometric pressure, and tectonic stresses', J. Geophys. Res., 77, 5825-5829.

White, D. E., R. O. Fournier, L. J. P. Muffler, and A. H. Truesdell (1975), Physical results of research drilling in thermal areas of Yellowstone National Park, Wyoming, U.S. Geol. Surv. Prof. Pap., 892, 70. 